\title{
LEARNING TO RESPECT OUR ELDERS: \\ AGING-IN-PLACE MODIFICATIONS IN TORONTO COMMUNITY HOUSING
}

by

Alexandra Weiss

Bachelor of Arts (Honours), McMaster University, 2011

\section{A Major Research Paper}

Presented to Ryerson University

In partial fulfillment of the requirements for the degree of

\author{
Master of Planning \\ in the Program of \\ Urban Development
}

Toronto, Ontario, Canada, 2013

(C)Alexandra Weiss 2013 
AUTHOR'S DECLARATION FOR ELECTRONIC SUBMISSION OF A MRP

I hereby declare that I am the sole author of this MRP. This is a true copy of the MRP, including any required final revisions.

I authorize Ryerson University to lend this MRP to other institutions or individuals for the purpose of scholarly research

I further authorize Ryerson University to reproduce this MRP by photocopying or by other means, in total or in part, at the request of other institutions or individuals for the purpose of scholarly research.

I understand that my MRP may be made electronically available to the public. 


\title{
LEARNING TO RESPECT OUR ELDERS: \\ AGING-IN-PLACE MODIFICATIONS IN TORONTO COMMUNITY HOUSING
}

\author{
(C)Alexandra Weiss 2013 \\ Master of Planning \\ in \\ Urban Development \\ Ryerson University
}

\begin{abstract}
This paper examines the feasibility of seniors physically aging-in-place within Toronto Community Housing Corporation's (TCHC) portfolio. Due to the demographic shift that the City of Toronto and TCHC will experience in the upcoming decades, there will be a greater need to ensure that tenants are provided with safe accommodations to foster aging-inplace. Being able to provide this to senior tenants will require that several modifications be made to units, and tenants and TCHC will share this responsibility. These modifications must comply with the policies in place, and be feasible within constrained budgets. This research outlines the key unit modifications required for aging-in-place to occur, and highlights their costs and impact on tenants and TCHC, which ultimately helps determine the feasibility of implementing aging-in-place modifications. The imperative on tenants, TCHC and higher orders of government is detailed so they can take proactive measures in accommodating for this subset of seniors.
\end{abstract}

Key Words: Aging-in-Place, Seniors, Home Modifications, Toronto Community Housing Corporation 


\section{Acknowledgements}

I would like to thank my supervisor, Dr. Joseph Springer, who helped me sort through a tangle of ideas and keep this research to a manageable scope. He also provided me with guidance, positive feedback, and insight at every step of the way.

To Andrea Austen (Policy Development Officer) and the rest of the policy staff at the City of Toronto Social Development, Finance and Administration Division, thank you for providing me with the opportunity to work on the Seniors Strategy. This work inspired me to research seniors and strive to help them to continue to fulfill their golden years on their own terms.

I would like to thank Eugene Jones Jr, President and CEO of Toronto Community Housing Corporation for showing an interest in this research and understanding the needs of senior tenants.

Lastly, thank you to my parents and sister for supporting me at every step of the way in my twenty years of education. 


\section{Dedication}

This research is dedicated to my late grandparents who taught me to respect my elders and demonstrated how to be strong, feisty seniors who aged-in-place for as long as safely possible. My parents continue to inspire my research, and I hope in thirty years that they will be able to safely age-in-place with the help of home modifications. 


\section{Contents}

INTRODUCTION

PROBLEM

PURPOSE

METHODOLOGY

DOCUMENT REVIEW

FiEld Visits AND Pricing Method

STUDY LIMITATIONS

DEFINITIONS

TCHC CONTEXT

BACKGROUND AND CONTEXT

DEMOGRAPHICS

INCOME

ACTIVITY LIMITATIONS

AGING-IN-PLACE

HOME MODIFICATIONS

GENERAL MODIFICATIONS

KITCHENS

BATHROOMS

Choosing Modifications

UNFEASIBLE MODIFICATIONS

STRUCTURE TYPES TO MODIFY

CuRRent TCHC Plans

BUILDING TYPOLOGY

BuILDING AGE

BUILDINGS TO MODIFY

MODIFICATION PROCESS

Tenant Policy Framework

Provincial, MUNICIPAL AND TCHC POLICY FraMEWORK

MODIFICATION RESPONSIBILITY

FINANCIAL IMPLEMENTATION

MODIFICATION COST SCENARIOS

BATHROOM

IMPACT ON TCHC BUDGET

Examples of Funding Programs Currently Available
11

11

11

12

14

16

17

19

20

23

24

27

27

28

29

29

31 
TENANT IMPERATIVE

HOW TO GET THERE?

MODIFICATION RECOMMENDATIONS

POLICY RECOMMENDATIONS

FINANCIAL RECOMMENDATIONS

CONCLUSION 


\section{List of Figures and Tables}

Figure 1: Income of Senior Renters in Toronto ........................................................................... 12

Figure 2: Percentage with Conditions that Limit Daily Activity in Toronto................................ 13

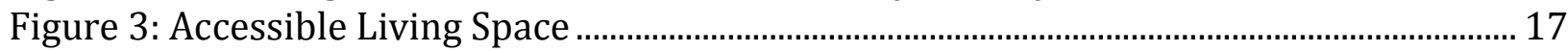

Figure 4: Door Accessibility - Clear Swing Hinge and Lever Door Handle ................................ 18

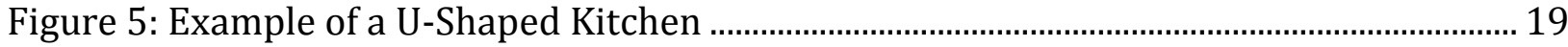

Figure 6: Raised Toilet Seat Cover...………………………………………………………... 21

Figure 7: 'Wet Room' Accessible Shower and Walk-In Bathtub ................................................. 22

Figure 8: Grab Bars.............................................................................................................................. 22

Table 1: Unit Evaluation Checklist ............................................................................................... 24

Table 2: Tenant and TCHC Modification Responsibilities............................................................ 34

Table 3: General Modifications Moderate Cost Scenario............................................................... 37

Table 4: General Modifications Minimum Cost Scenario.............................................................. 38

Table 5: Bathroom Modifications Premium Cost Scenario ............................................................. 39

Table 6: Bathroom Modifications Moderate Cost Scenario .......................................................... 40

Table 7: Bathroom Modifications Minimum Cost Scenario ......................................................... 41

Table 8: Cost Summary for TCHC Modifications Using Minimum Scenarios.............................. 42 


\section{Introduction}

Housing is a crucial support for healthy aging. Housing influences several important physical and psychological aspects of wellbeing including but not limited to, active living, independence, and social and civic participation. Aging-in-place has become an increasingly popular alternative to age-segregated retirement communities as it allows seniors to remain in their own homes and communities and fosters continued autonomy (Bookman, 2008). The living arrangement trends from the 2011 Census support the belief that more and more seniors are aging-in-place. On the national scale, $92.1 \%(4,551,905)$ of seniors live in private households or dwellings, while $7.9 \%(393,095)$ live in collective dwellings such as residences for senior citizens or health care related facilities (e.g. nursing homes, chronic care, long-term care hospitals) (Statistics Canada, 2011). However, without the proper resources, continuing to live at home as one ages is not necessarily feasible. Furthermore, aging-in-place is a challenge for those with low and moderate income due to the wide array of social, financial, home maintenance and modification services that are required in order to meet basic needs and fulfill the preferences of seniors (Davey, 2006; Fisher et al., 1999).

Over the next decade, the number of seniors living in Toronto will increase dramatically. According to the 2011 Census, 518,400 people living in the city of Toronto were over the age of 59 (Statistics Canada, 2011). It is important to note that within the next twenty years, 758,850 Toronto residents will transition into the senior citizen age category (individuals aged 65 and over) (Statistics Canada, 2011). This demographic shift has several implications. Associated with this large aging population, three main areas have received a great deal of attention: health care impacts, a shrinking labour force and caregiving. Beyond these areas, it is important to consider where and how seniors are going to live, which will in turn require that there is an appropriate housing stock for older Torontonians.

Due to the increased barriers that those of low and moderate incomes face when it comes to the housing infrastructure component of aging-in-place, this research will focus on 
seniors in Toronto Community Housing Corporation (TCHC) buildings. This will include the demographic composition of TCHC residents, and the specific barriers that these residents face.

Currently, more than 26,000 seniors (tenants aged 59 or old) live in TCHC seniorsdesignated and mixed properties. Furthermore, more seniors will be living in mixed buildings as the tenant population ages across the city and it is expected that the senior population in TCHC housing will grow $35 \%$ by 2020 (TCHC, 2008). Within the TCHC portfolio there are 66 senior designated buildings which house $56 \%$ of TCHC senior tenants, and more than 350 mixed use low- and high-rise apartment buildings that have seniors within them (TCHC, 2008). 


\section{Problem}

We are woefully unprepared to deal with the myriad consequences of this impending reality, nor have we challenged ourselves to imagine the opportunities that an aging [Canada] will present. It is certainly driven by well-defined factors, including the aging of the baby boom generation, dramatic increases in life expectancy that occurred in the twentieth century, and more recent compression of morbidity.

- $\quad$ Littlefield \& McNulty,2012, p. ix

The problem that TCHC faces is twofold. The first is that currently TCHC does not have a specific housing portfolio that meets the physical needs of seniors. The seniors designated buildings are only distinguished by the age of the tenant, rather than the layout of the physical structure, which does not necessarily mean that seniors are provided with appropriate housing to meet their physical needs. The second is that currently TCHC services an estimated 26,000 seniors and this population is forecasted to grow to over 37,000 by 2020 ( $\left.\mathrm{TCHC}_{1}, 2012\right)$. As evidenced by demographic information and trends in personal preferences, there is a need to ensure that these current and approaching seniors have 'adequate' housing and the opportunity to age-in-place in their current TCHC units. Being provided with adequate housing has been enshrined as an international law, encompassing that everyone has the right to adequate housing. This can be traced back to 1948 in the Universal Declaration of Human Rights, and there is a need to keep supporting this notion and providing everyone with adequate housing that complies with health and safety standards (Thiele, 2002). 


\section{Purpose}

It is evident that the vast majority of seniors have at least one chronic disease or condition, and as they age, their chances of living with chronic illness or disability will increase (Sinha, 2012). Therefore it is important to understand how to help plan and adapt to aging so that senior tenants can remain independent in the TCHC setting. The purpose of this research is to provide a comprehensive background report and analysis identifying how to physically modify the current seniors and non-seniors designated buildings in the TCHC portfolio. This research will also determine how feasible it is to design environments which will aid seniors in maintaining their independence, while allowing and promoting aging-at-home. As such, the research questions guiding this project are;

i. What are the key components of housing modifications that TCHC would have to do in order to provide a physical environment adequate for aging-in-place?

ii. What kinds of structures would be best to modify and renovate?

iii. Are these modifications financially feasible?

iv. What are the policy implications that flow from the analysis?

This research will strive to determine the current conditions of seniors in TCHC dwellings, and provide recommendations to improve the physical conditions that support their quality of life. It is important to note that quality of life stems from a variety of physical and social conditions, which are vital to creating elder friendly and appropriate communities.

In 2008, TCHC created a Seniors Implementation Framework, outlining four key pillars within their strategy: (1) buildings; (2) health and wellbeing, (3) community engagement; (4) culture of change and continuous learning $\left(\mathrm{TCHC}_{1}, 2012\right)$. Although these pillars all contribute to the quality of life of tenants, this research will examine the physical conditions for seniors within the units in the portfolio, and aim to ensure safe, adequate housing for senior tenants. 


\section{Methodology}

In order to research this topic substantially and to ensure the results and modification prices were current and relevant within the Toronto context, a mix of methods was used.

\section{Document Review}

The research for this study consisted of a literature and policy review in order to gain familiarity with the topic of aging-in-place, home modifications, and to gain insight into the TCHC portfolio, programs, policies, and financial resources and constraints. Through the examination of the literature and research on this topic, linkages to the TCHC and Toronto context, that provide greater relevance of this topic could be made. Sources examined include, but are not limited to:

- Academic literature and research;

- Accessible design resources;

- Government policies such as the Ontario Human Rights Code and Accessibility for Ontarians with Disability Act; and

- TCHC documents such the 2007 Accessibility Plan, and Annual Reviews

\section{Field Visits and Pricing Method}

In order to understand the scope of the modifications research conducted through document review, it was fundamental to collect the current prices per unit of the modifications. By conducting primary research on current cost it has been possible to ensure that the prices per modification reflect the local context and are reflective of what the modifications could cost senior tenants and TCHC in Toronto.

Each modification price was obtained by using a variety of sources from a range of senior specific homecare providers such as Shoppers Home Health Care and Motion Specialties. Furthermore, suppliers which offer specialized modifications such as bathtub replacements were contacted for estimates. For general home modifications such as lighting fixtures and door handles, a variety of home hardware sources were also used including, but not limited to, Home Depot, Home Hardware, Lowes, and Canadian Tire. These retailers all have a variety of home modifications, and after identifying the variety of modifications and differing prices, the least expensive version of the appropriate item was chosen, as the 
purpose of this research is to provide cost-effective scenarios that reflect the constrained TCHC budget. Furthermore, staff at the variety of retailers provided assistance in determining that the selected modifications were appropriate, and provided an indication of total costs and ease of maintenance and installation. Each item was inputted into spreadsheets in order to manipulate the prices to reflect the total cost based on the quantity necessary, which reflected the findings of the document review. Appendix A provides greater detail on where each modification price was collected.

\section{Study Limitations}

This research has several limitations. Chief among them was the difficultly of estimating labour costs as they are subject to collective and other labour agreements internal to TCHC. This would have to be internally evaluated in order to have an accurate approximate cost, and can be done in evaluating what resources and staff to utilize to complete these modifications.

While discussing the modifications with various informants and staff at the various retailers/suppliers, they indicated that price negotiations could be made when buying the modifications such as grab bars in bulk. However, without having more specific demand estimates, these bulk costs and contracts could not be made. With adequate negotiations and buying these modifications in bulk, the estimate per unit modification costs could be reduced from what is identified within this research. This research was also not able to include contingency costs that would be associated with the modification process, and would ultimately alter and raise the cost of modifications.

Despite these limitations, the costs outlined provide an accurate per modification cost of the various modifications using local Toronto sources. 


\section{Definitions}

For further clarity, several key terms will be defined to ensure accuracy and standardization. These definitions have been identified through research, and reflect current literature and industry best practices.

\section{Senior}

The term senior is important to define as it is often used interchangeably with terms such as elderly and retired, in addition to being associated with different ages. For this research project, the definition of senior will correspond to TCHC's definition, which is a person aged 59 and over $\left(\mathrm{TCHC}_{1}, 2012\right)$.

\section{Housing}

Although tenants of TCHC are renting their dwellings, the notion is that these dwellings represent their own home. The term housing will be defined as "a physical structure within which a self-selected household lives. It is a place in which the basic human activities of sleeping, eating, washing, storage of possessions, social contact, recreation, and care within the self-selected household take place" (Heywood, 2001).

\section{Adequate Housing}

For this research, adequate housing is defined as more than just a roof over one's head. Adequate housing will also incorporate adequate privacy; adequate space; physical accessibility; structural stability and durability; adequate lighting, heating and ventilation; adequate basic infrastructure, such as water supply, sanitation and waste management facilities; and suitable environmental quality and health-related factors, all of which should be available at an affordable cost (United Nations, 1996).

\section{Aging-in-Place}

Aging-in-place (commonly referred to as aging-at-home) will be defined using the United States of America Center for Disease Control's definition that was commonly found in the literature. In the context of this research, aging-in-place will be defined as "the ability to 
live in one's own home and community safely, independently, and comfortably, regardless of age, income, or ability level" (CDC, 2012).

\section{Modification}

Modification is defined as conversions or adaptations to the permanent physical features of the home environment to reduce the demands from the physical environment to make tasks easier, reduce accidents, and support independent living (Tanner et al., 2008). For the purpose of this study, this term is used interchangeably with renovation. 


\section{TCHC Context}

In order to understand the scope of this research, the locational context and role of TCHC is crucial to examine. Toronto and the TCHC portfolio have been chosen as the primary case study in order to answer the aforementioned research questions. TCHC is the largest provider of social housing in Canada, and the second largest in North America as it houses an estimated 164,000 low- and moderate-income residents (TCHC, 2012a). Their extensive portfolio of affordable, market value and subsidized (rent-geared-to-income) housing contains 58,500 households, within more than 2,200 buildings including high-, mid-, and low-rise apartments, townhouses and stand-alone houses (TCHC, 2012a).

Within the TCHC portfolio, there are 66 seniors designated buildings, which provide housing for tenants aged 59 or over. These buildings are only designated based on the actual age of tenants, who must be over the age of 59 to qualify. There is no physical difference between the seniors housing portfolio and the rest, meaning that the units in seniors buildings are not physically structured to meet the needs of seniors. As such, TCHC seniors buildings are not necessarily accessible, and may not contain the physical components some seniors require for their safety and the preservation of their independence (e.g. grabs rails, safe flooring).

Since senior tenants are located throughout the TCHC portfolio, for this research, all of the seniors and non-seniors designated buildings are included, as all housing could and should allow aging-in-place to occur and should be promoted.

The role and mandate of TCHC is to ensure that affordable housing is provided to low- and middle-income residents in Toronto, and to make certain that tenants are connected to services and opportunities, in order build healthy and supportive communities (TCHC, 2012a). The mandate is achieved if TCHC's identified outcomes, including safe communities, equitable and inclusive life opportunities, and buildings that are maintained and in good repair are met. 
TCHC is first and foremost a landlord and within this role it strives to promote successful tenancies. This includes both landlord and tenants meeting their respective obligations. A TCHC established a Successful Tenancies Strategy (2010) in order to connect tenants with the support they need in order to thrive in their communities (TCHC, 2012e). There are a variety of vulnerable tenant groups that have been identified including tenants with mental illness, however seniors are considered to be the largest proportion of vulnerable populations within the TCHC portfolio. In order to deal with this subset of the tenants, TCHC as a landlord must provide suitable housing, and address unhealthy unit conditions. In order to do so, TCHC inspects units at least once a year in order to ensure that they are safe (TCHC, 2012e). Although health and safety is examined at the unit-by-unit scale, there remains a disconnect regarding what is being done to promote senior safety and accessibility. It is crucial to examine the role of TCHC in regard to aiding senior tenants, and providing opportunities for tenants to safely age-in-place and have greater flexibility in terms of aging on their own terms. 


\section{Background and Context}

As discussed, there will be a demographic shift occurring in Toronto and within the TCHC tenant portfolio over the next several decades. The TCHC seniors population is expected to grow by $35 \%$ in 2020 , and it is vital to understand the demands and necessities this large cohort of seniors will have on the TCHC housing portfolio (TCHC, 2008). In order to understand the housing needs of this subset of seniors, a demographic review of Toronto and TCHC tenants was undertaken to better examine the lifestyles, housing trends and financial resources of seniors.

\section{Demographics}

It is anticipated that the sharp demographic rise that Toronto and TCHC will experience will be challenging, as housing needs, demands, and preferences will change. At the citywide level, one in six city residents are projected to be age 65 and older by 2021. Like Toronto, TCHC is on the verge of experiencing a significant increase in its senior population, and the projections show that this trend will continue. By 2021, there will be an estimated 35,100 tenants over 59 years of age within the TCHC portfolio, which will be approximately 1 in 5 tenants (TCHC, 2012a). It is vital for TCHC to understand the demands this large cohort of seniors will place on the existing housing portfolio.

\section{Income}

For this research, the household income of senior renters in Toronto has been examined. These variables are important to consider in order to assess the reliance on affordable rental options amongst seniors due to their income limitations, which will affect the demand for TCHC units. Renters have been selected based on the form of tenure that TCHC offers. The graph below illustrates the household income of senior renters in Toronto generally, including senior renters in TCHC buildings. 
Figure 1: Income of Senior Renters in Toronto

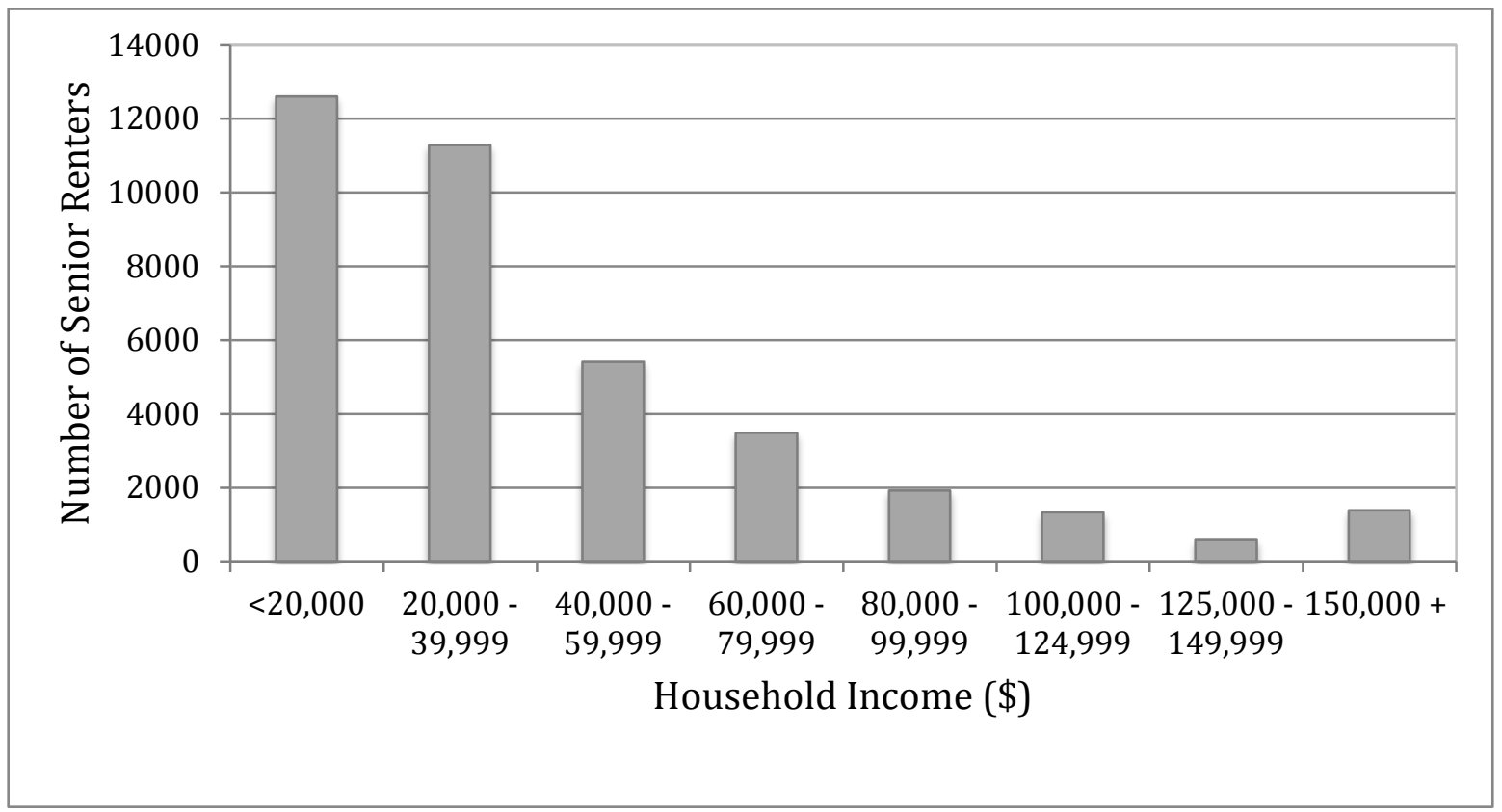

Source: City of Toronto, 2012

As Figure 1 illustrates, the majority of senior renters have household incomes of less than $\$ 40,000$, with a significant portion having less than $\$ 20,000$. According to the City of Toronto data set, there are 23,895 senior renters in Toronto with household incomes of less than $\$ 40,000$, and 12,605 with household incomes of less than $\$ 20,000$ (City of Toronto, 2012). It is evident that many seniors in Toronto do not have adequate disposable incomes, which limits their ability to meet their needs, and increases their reliance on TCHCs rent-geared-to-income units. This provides a greater incentive to ensure that senior supportive housing within the TCHC portfolio exists.

\section{Activity Limitations}

In order to understand the need for housing modifications and the promotion of increasingly accessible housing units, it is important to highlight the activity limitations that exist as people age. Conditions that limit daily activities will have significant impacts on TCHC senior tenants, therefore there must be a reassessment of the housing options to accommodate for these conditions. The basic activities of daily living include walking, toileting, or bathing. 
Figure 2: Percentage with Conditions that Limit Daily Activity in Toronto

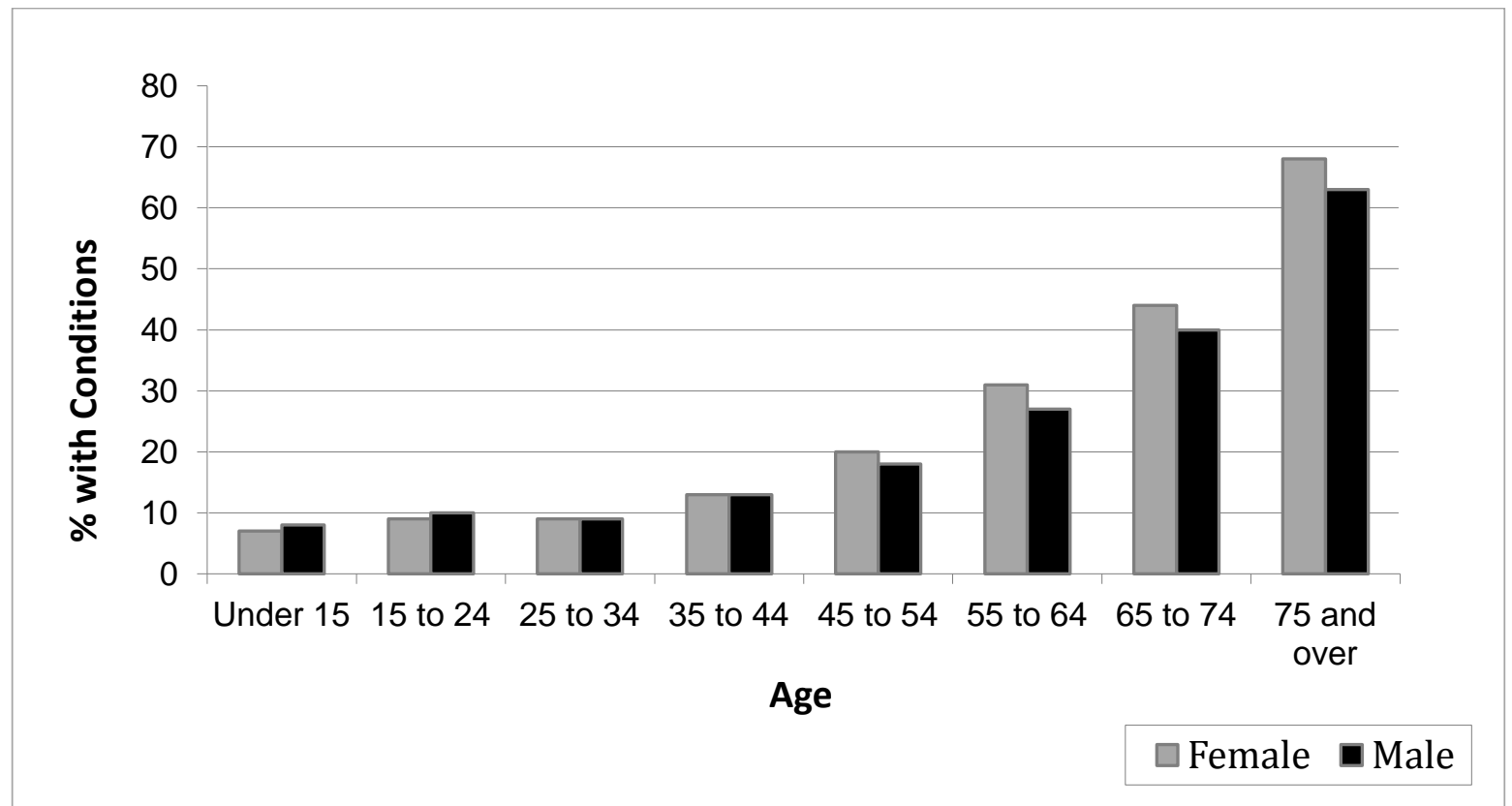

Source: City of Toronto, 2012

As illustrated by Figure 2 above, older cohorts are most likely to have conditions that limit their daily activities. Among those 65 to 74, less than half have activity limitations, compared to nearly two thirds for those aged 75 or older (City of Toronto, 2012). Understanding the correlation between ability and age provides a further need to examine how the TCHC portfolio will accommodate this trend. 


\section{Aging-in-Place}

With a greater understanding of the demographic shift which will occur, and the lifestyle of this population, it is important to examine housing trends and preferences. The growing phenomenon of aging-in-place promotes the idea of allowing seniors to fulfill their "golden years" unconstrained in their own home, and remain in their own communities (Bookman, 2008; Fisher et al., 1999; Mynatt et al., 2000; Davey, 2006). However, academics and professionals stress that aging-in-place is only recommended when seniors are in a safe, comfortable, suitable environment, that is also connected to elder care agencies in their local community (Bookman, 2008; Fisher et al., 1999). It is noted that there is a consensus that seniors want to remain in their own homes and communities and defer entering institutional settings such as nursing homes, or age-segregated communities (Bookman, 2008; Fisher et al., 1999; Mynatt et al., 2000; Davey, 2006).

According to $\mathrm{CMHC}, 85 \%$ of Canadians over the age of 55 years want to remain in their present home for as long as possible, even if/when they face changes to their mobility and health (CMHC, 2012a). This trend was also noted in a nationwide study conducted in the United States, which illustrated that $89 \%$ of respondents aged 55 and older agreed strongly with the statement "What I'd really like to do is stay in my current residence for as long as possible" (NAHB, 2005). Additionally, $72 \%$ of respondents had not made any future plans for where they will move when it becomes unsafe for them to remain in their own home (NAHB, 2005). CMHC noted that in general, seniors want and expect to age-in-place, and do not want to consider alternative options or make necessary modifications until circumstances force them to do so (CMHC, 2012).

Although aging-in-place is a preferred method of aging, there are several challenges identified within the literature relating to this trend, in particular those reflecting the built environment and accessibility. A major consideration regarding housing not being built for seniors is the age of the development. A significant phase of production of Canadian social housing took place between 1949 and 1984, and during this period the housing was primarily geared towards families. It wasn't until the end of this time frame that there was an emphasis on seniors (Smith, 1995). Due to the age of the housing stock, the dwellings 
were built based on National Housing Act minimum standards that do not reflect those of modern day (Smith, 1995). This presents a challenge to seniors aging-in-place, as the physical design is not necessarily adequate for housing an elderly person (Smith, 1995 ; Kose, 1997). A major theme found in the literature is the evidence that there is a large discrepancy between the design of buildings and communities, and the needs of an aging population (Bookman, 2008). Specifically, mixed age buildings are designed for mobile populations. These spaces are typically organized to accommodate people who are healthy and not adversely affected by distances. Design elements such as split-levels, flooring, and bathroom facilities can ultimately pose threats to seniors, and have been criticized for increasing the risk of falls, which is the fourth leading cause of death for seniors in the United States (Bookman, 2008; Fisher et al., 1999). 


\section{Home Modifications}

Through the examination of these challenges, it has become evident that all dwellings are not necessarily adequate for housing seniors, and promoting aging-in-place. In order to overcome this challenge, housing modifications are necessary (Bookman, 2008; Fisher et al., 1999; Kose, 1997). Making adaptations to the built form can be considered the best solution, and it would be advantageous for this to take place sooner rather than later (Kose, 1997). In order to overcome the challenges identified, the idea of physical retrofitting of existing projects is considered the most favourable solution to deal with shortcomings in the original design, and to promote aging-in-place (Fisher et al., 1999). Furthermore, it is considered a more efficient and effective approach than creating new senior specific buildings (Fisher et al., 1999). Modifying existing homes is deemed to be a viable way to improve accessibility and safety, and modifications should incorporate the universal design model. This approach encompasses the notion of producing dwellings and environments that are inherently accessible for a broad spectrum of human ability (Taira et al., 1999). The main benefit of investing in home modifications is that they foster autonomy and act as a preventative measure in preventing accidents. According to the National Centers for Disease Control and Prevention, home modifications and repairs can prevent an estimated $30-50 \%$ of all home accidents among seniors such as falls (CareCorner, 2011).

The following home modifications are based on the recommendations found in Canada Mortgage and Housing Corporation's (CMHC) Accessible Housing by Design, and Elder Design. They reflect the necessary modifications, and correspond to, and reinforce the various modifications outlined in the literature at large. All modifications will be categorized according to the function of the room in question in order to gain an understanding of the scope and variations of modifications that exist for aging-in-place.

All of the modifications discussed below will strive to promote accessibility by removing or overcoming barriers, and meet the needs of all users so that they continue to live independently and safely. Common design modifications made to dwellings in order to make them appropriate for aging-in-place include: the installation of grab rails in critical 
places such as hallways, baths and showers, lower cupboards in kitchens, level floors, and negotiable circulation routes (Bookman, 2008; Smith, 1995; Kose, 1997; Fisher et al., 1999).

\section{General Modifications}

Although there are several key

modifications that have been

identified for specific rooms within

a dwelling, there are some

modification recommendations

that have been identified for

implementation throughout the

entire dwelling. Overall, it is

recommended that dwellings

should follow an open concept plan,

encompassing fewer doors and

hallways, and there should be

rooms that flow into one another,

Figure 3: Accessible Living Space

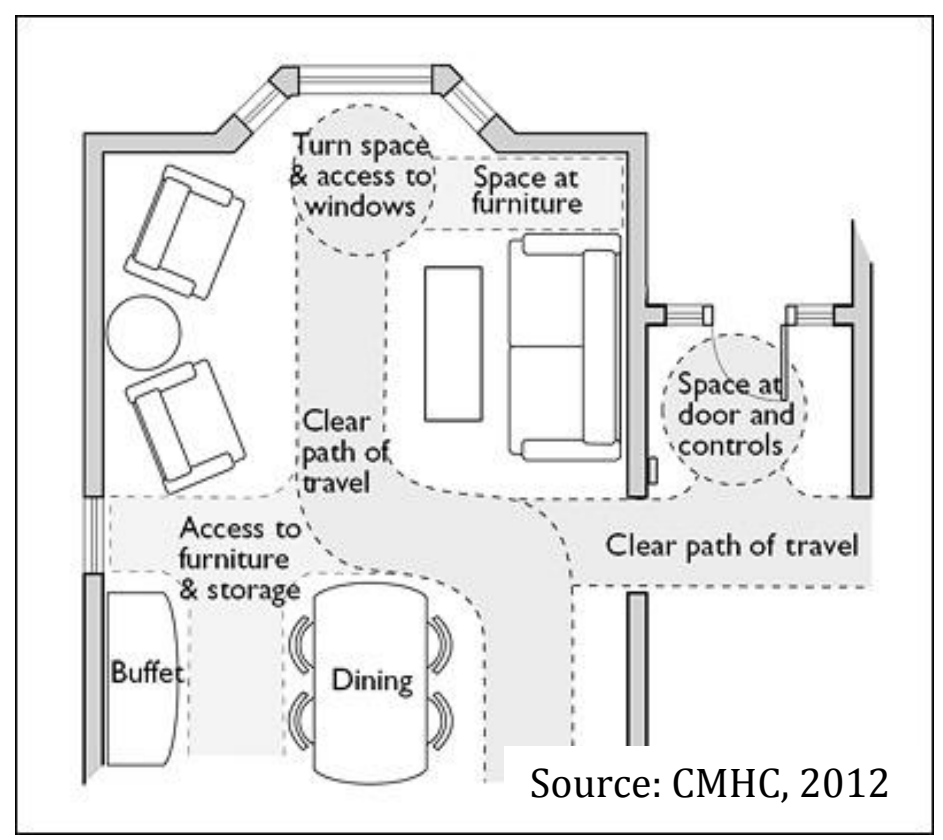

as illustrated by Figure 3 (CMHC, 2012). Additionally, rooms should be strategically placed. For example, the kitchen should be adjacent to the dining room, while the bedroom should be close to a bathroom. A key component of modifying housing to promote aging-in-place is to consider the distances between the rooms due to the potentially compromised stamina tenants may have (CMHC, 2012). For modification purposes, room purposes can be converted to promote accessibility, such as a seldom-used dining area being converted into a den or a bedroom. An important feature of modification is to have an adequate open area to allow for circular turning space, primarily for tenants with wheelchairs or walking aids (CMHC, 2012). This often requires repositioning elements within the dwelling such as storage and appliances.

Another key element is the replacement of doors to reflect accessibility for those aging. On hinged doors, having a proper handle is considered to be an inexpensive modification to 
aid in aging-in-place. Replacing standard door hinges with swing-clear hinges will widen the doorway, resulting in an additional clearance of at least 2 inches. Additionally, due to diminishing hand-eye coordination and conditions such as arthritis, handles should be able to be operated with one hand, and should not require tight grasping or twisting of the wrist. The ideal handle would be a lever (Bakker, 1997; CMHC, 2012). Furthermore, to accommodate for arthritis and other prevalent joint conditions that may reduce motor skills, changes can be made to the knobs on drawers and cabinets by installing large $\mathrm{C}$ handles (Bakker, 1997).

\section{Figure 4: Door Accessibility - Clear Swing Hinge and Lever Door Handle}

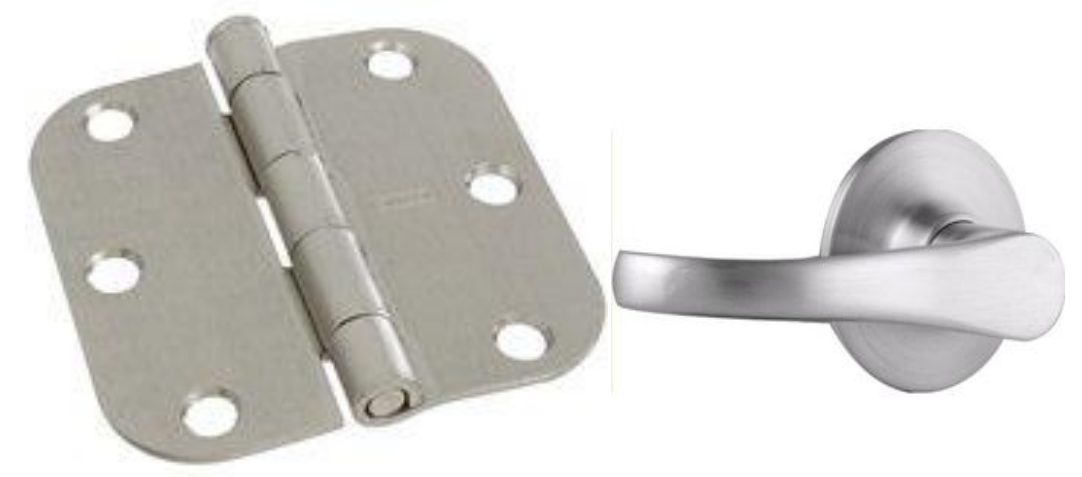

Source: Lowes Canada, 2013; Home Hardware Canada, 2013

Lighting considerations are also a modification to be applied to the entire dwelling since less acute vision is commonly experienced among those aging (Bakker, 1997). This encompasses providing better light for paths to ensure safety and visibility, especially along hallways and stairs (Bakker, 1997; CMHC, 2012). When providing additional lighting to units, it is important to consider and examine the quality and quantity of lighting (Bakker, 1997). A variety of lighting choices have been identified as appropriate for aging tenants. The first is Chromalux Lighting, which provides a full spectrum of lighting, and closely resembles natural light, providing the clearest colour with minimal glare. This type of lighting can be found in regular light bulbs, as well as in fluorescent tube lighting, which provide brighter light and are relatively inexpensive to both purchase and to operate 
(Bakker, 1997). Fluorescent lighting choices and fixtures are considered preferable due to their relatively minimal expense in relation to the lifespan per bulb. Furthermore, sensor switches and lights, and night-lighting, are recommended as they can detect movement and turn on automatically, which can help with declining night-vision amongst elderly people. It is recommended that permanent fixtures be installed along the hallways near bathrooms and bedrooms to prevent falls (Bakker, 1997; CMHC, 2012). All of these features provide proper lighting, ultimately making all surfaces such as floors more visible.

Changing flooring materials is important in order to not only make cleaning easier, but also to enhance safety. Flooring should also be modified throughout the unit so that senior tenants can avoid moving from one surface to another, which can be hazardous. Therefore, one material should be used throughout the entire unit other than the bathroom and kitchen (Bakker, 1997). Marble and waxed floors should be avoided, as they can get slippery and pose safety threats. Materials such as vinyl or linoleum resilient sheet flooring should be used as they are softer underfoot and can help cushion a possible fall (Bakker, 1997; CMHC, 2012). Additionally, it has been noted that these options are more cushioned compared to ceramic tiles, which in cases of a fall, can be less detrimental to tenants (CMHC, 2012).

\section{Kitchens}

There are several key modifications that should be made in the kitchen due to its important role in the daily lives of tenants, and the typical amount of time spent in it. The purpose of kitchen modifications is to promote the function and flexibility of the space. In order to do this, efficient design, maneuvering space, adaptability, and safety are key themes within each of the proposed modifications. There are a

Figure 5: Example of a U-Shaped Kitchen

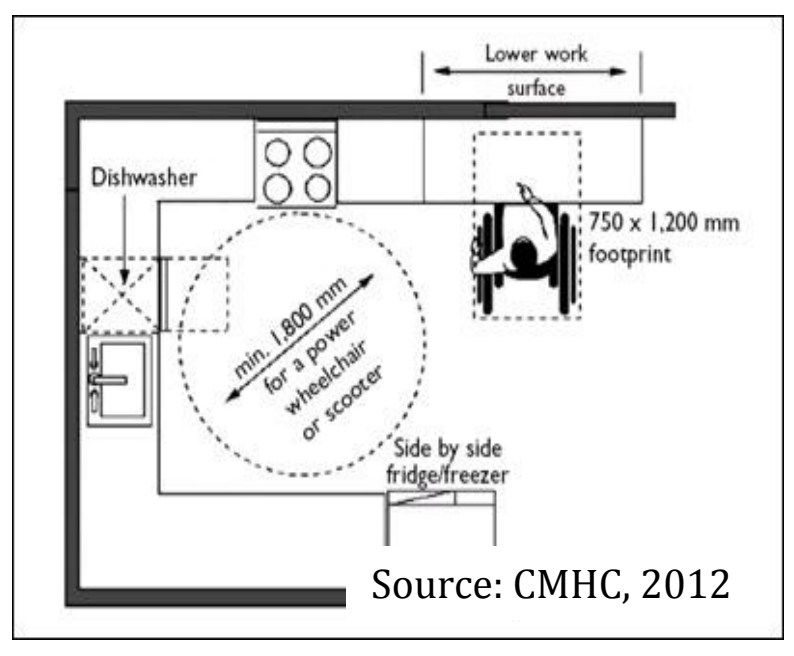
variety of common compositions which the kitchen could follow including, but not limited 
to, U-Shaped kitchen, Gallery Style, and L Shaped. However, U-Shaped kitchens, as illustrated by Figure 5, are deemed to be the most convenient layout for aging-in-place as they provide enough turning space, and more than one entry and exit point (CMHC, 2012).

Implementing such formed kitchens would require extensive renovation to the current layout of kitchens in the various TCHC dwellings, therefore there are several simpler modifications that can be made. The typical design of the kitchen has focused on a compact form, revolving around the sink, stove, and refrigerator (CMHC, 2012). However, the form should incorporate a variety of additional kitchen elements such as work areas. Promoting efficiency within the kitchen environment by carefully considering the location and relationship of all the major features can promote an accessible kitchen for aging tenants. Achieving this includes simply arranging storage, work areas, and appliances to reflect logical and sequential movements, such as putting storage units for pots and pans near the stove (CMHC, 2012).

Another adaptation is lowering countertops, drawers, and shelves to meet the needs and the reaching abilities of aging tenants (CMHC, 2012). More specifically, upper cabinets should be hung 12 inches from the countertop, rather than the accepted 18-24 inches above the counter to provide further accessibility (Bakker, 1997). Railings can also be installed on the edge of countertops, as they provide additional safety measures for those with balance problems (Bakker, 1997).

\section{Bathrooms}

There are several modifications that should be done to bathrooms as it is a common space where accidents occur. Bathrooms are frequently used, and therefore should foster maximum safety and accessibility. Modifications should be focused on toilets, bathtubs, showers, as well as smaller adaptations such as flooring and grab rails. It has been noted in the relevant literature that toilets for aged populations should be slightly higher than standard ones as they are easier for tenants to get up and down from. A simple mechanism to implement this is by supplying tenants with raised toilet seat covers to aid them in 
transferring from a wheelchair, as well as help relieve strain for seniors with arthritic knees (Bakker, 1997; CMHC, 2012).

\section{Figure 6: Raised Toilet Seat Cover}

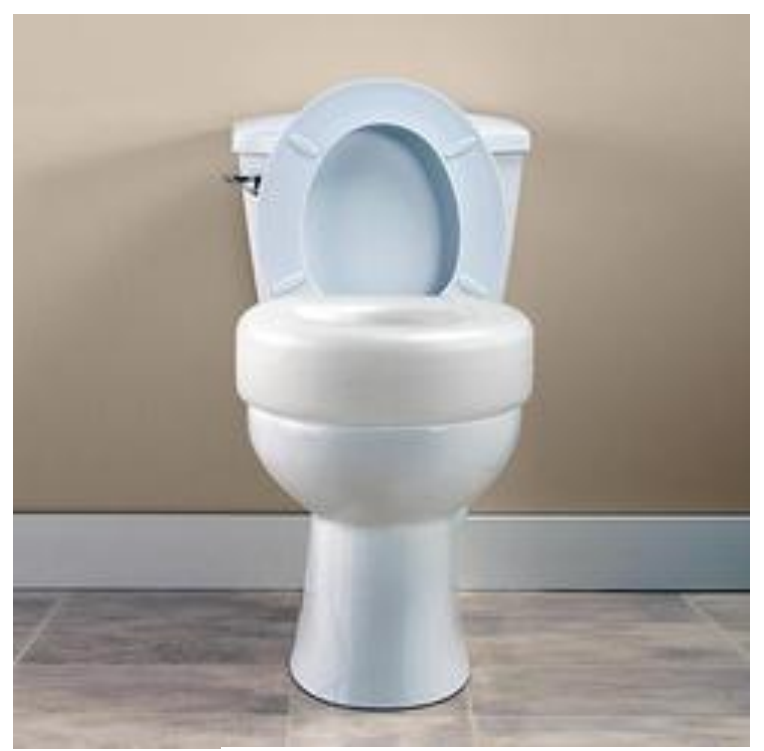

Source: Sears Canada, 2013

Showers and bathtubs are the most common place for falls in the home, therefore there are several modifications that can be applied. Showers can be renovated to become more accessible, and for example can be transformed into 'wet rooms', which are large tiled floor areas with a showerhead and room for a shower seat to be installed. This eliminates challenges associated with bathtubs such as entry and exit, which could help in ultimately reducing the risk of falls (CMHC, 2012). However, this is one of the most expensive modifications, and is not feasible within TCHC units due to cost, disruption caused to tenants, and limited space. Walk-in-bathtubs are seen as a better investment as they can be installed in one piece. They have doors that allow for easy entry, and built-in seats (Bakker, 1997; CMHC, 2012). Clamp on bath rails also can be added to provide greater stability around the edge of the tub. The retrofit of the bathtub and accessories can help decrease the risk of personal accidents within the home, as there will be increased accessibility and the elimination of several hazards including the acrobatics that are required to get in and out of bathtubs (Bakker, 1997). 
Figure 7: 'Wet Room' Accessible Shower and Walk-In Bathtub

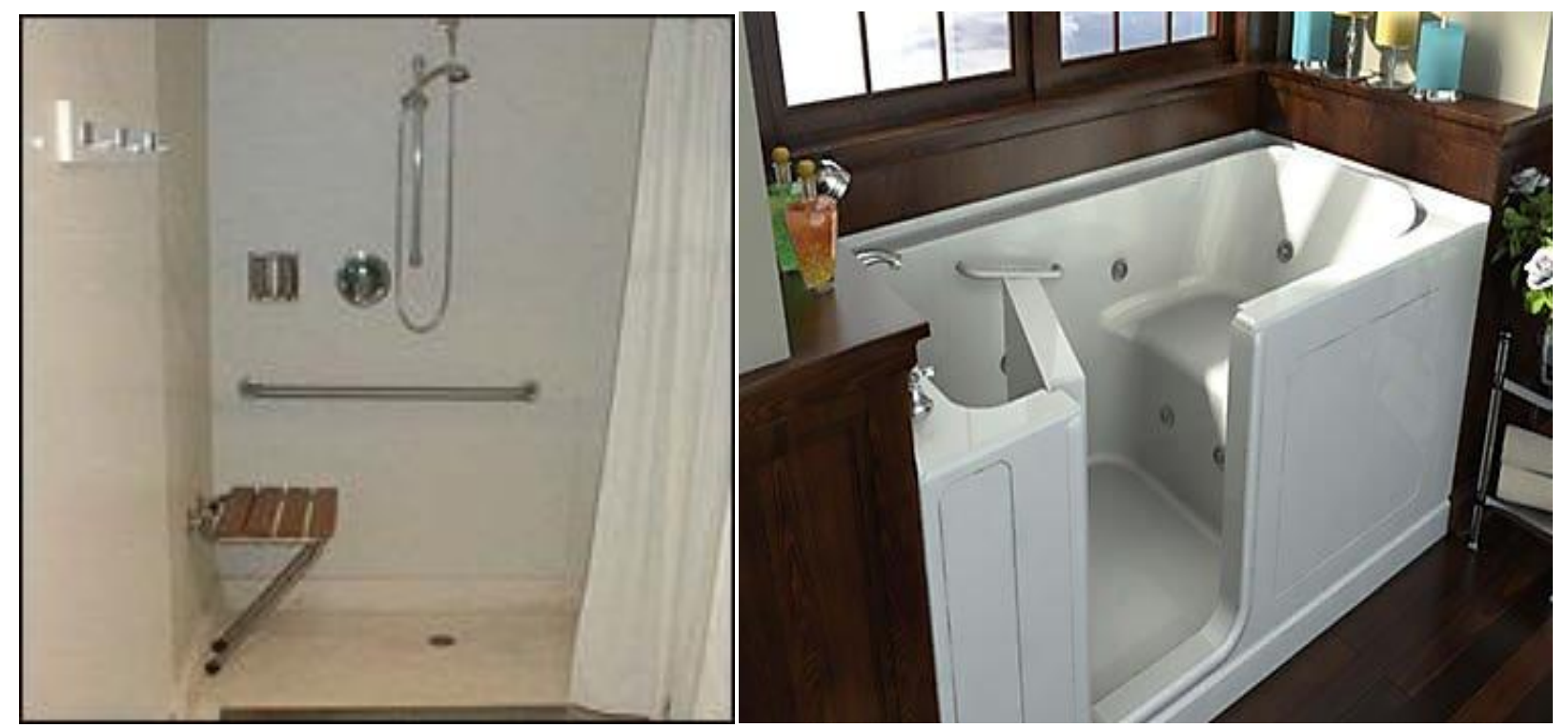

Source: CMHC, 2012; Carbon Free Homes, 2013

In order to ensure that bathrooms are

appropriate and safe for an aging tenant, a necessary and relatively inexpensive bathroom adaptation is the installation of grab bars in key areas, such as beside the toilet, and near and in the shower and/or bathtub (Bakker, 1997; CMHC, 2012). Grab bars should be mounted directly onto the bathroom wall, which require installation using long screws into wall studs. Another alternative is a wall unit that can be swung up out of the way and should be installed near the toilet. These provide stability and additional balance for tenants (Bakker, 1997; CMHC, 2012).
Figure 8: Grab Bars

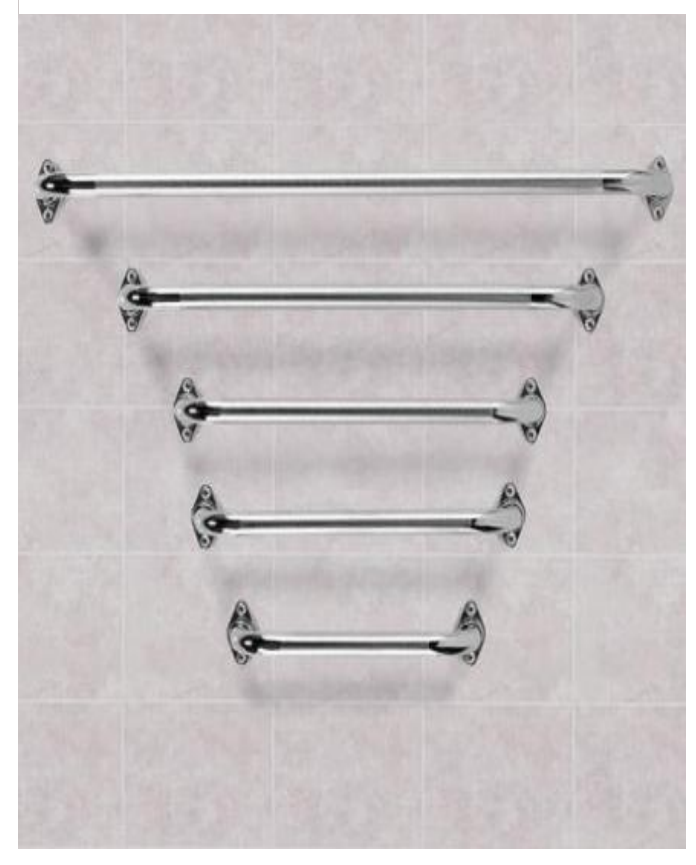

Source: Sears Canada, 2013 
The modifications previously discussed are considered to be key adaptations to create a barrier free physical environment, and illustrate that dwellings can be made safer and more livable for seniors as a result of both small and large design changes (Kose, 1997; Fisher et al., 1999).

\section{Choosing Modifications}

According to the U.S Department of Health and Human Services, in deciding and planning for which modifications are appropriate for aging-in-place, modifications should improve features of a home including, but not limited to, accessibility and adaptability. Improving accessibility encompasses elements such as widening doorways, and lowering countertop heights. Adaptability features are key as they are changes that can be made quickly to accommodate for the changing needs of tenants without having to completely redesign the home. These are considered 'quick wins' as they require fewer resources and planning such as installing grab bars in the bathroom (U.S. Department of Health and Human Services, 2003).

In determining what modifications should be implemented, it is important to assess the current and future needs of the tenant. Needs and ability will differ from one tenant to another, therefore there is not a one size fits all modification solution. There is a large spectrum of seniors, and age does not necessarily reflect the ability of the tenant. Therefore, the majority of the modifications outlined are centred around the concept of universal design that can help accessibility for everyone. Illustrated below in Table 1 is a sample of a unit evaluation checklist that will help aid tenants and TCHC determine what modifications need to be made in order to improve the accessibility and safety of the tenant within their unit. The questions are based off of the Elder Design (Bakker, 1997) home evaluation audit. 


\begin{tabular}{|l|l|l|}
\hline \multicolumn{2}{|l|}{ Yes } & \multicolumn{1}{|c|}{ No } \\
\hline General & & \\
\hline All doors have lever handles rather than round door knobs? & & \\
\hline Are all doorways 32 inches wide or more? & & \\
\hline $\begin{array}{l}\text { Is bright light available for each specific activity area } \\
\text { (bathroom, kitchen)? }\end{array}$ & & \\
\hline Is there level lighting throughout the home, including & & \\
hallways? & & \\
\hline Does the entrance to every room have sensor light switches? & & \\
\hline $\begin{array}{l}\text { Are there night lights in hallways, bathrooms and/or } \\
\text { bedrooms? }\end{array}$ & & \\
\hline of the tub)? & & \\
\hline Are there securely attached grab bars in the bathtub or shower \\
area?
\end{tabular}

Table 1 helps create an inventory of every unit and understand the level of accessibility and barriers that are present at a unit by unit scale. Furthermore, it helps tenants and TCHC determine what modifications have to be implemented.

\section{Unfeasible Modifications}

As previously discussed, replacing the current flooring material to one which is deemed safer and softer, such as vinyl or linoleum, is a key modification to do throughout the entire 
unit, in particular the kitchen and bathroom. However, several challenges have been identified in completing this modification including, but not limited to, removing all the existing flooring materials, covering the floor with padding and protection, and installing new materials. This process requires an extensive amount of labour, which is costly, and the process can take several weeks, disrupting the tenant and sometimes requiring temporary relocation. In addition to the modification process, the costs of $\$ 1.15$ - $\$ 3.10$ per tile have also been noted to be unfeasible. Due to the labour, potential disruptions to tenants, and the cost of the material, these modifications have been excluded from further analysis due to the challenges associated with them.

\section{Kitchens}

Although kitchen modifications have been identified as necessary spaces to modify to accommodate for aging tenants, the costs have been identified as too significant and not feasible for TCHC. In order to modify the kitchen based on the criteria identified within the literature, there is a large range of estimated costs for a kitchen remodel. The estimated range is from $\$ 15,000$ to $\$ 45,000$ per unit depending on the scale of modifications and cost of labour. This remodel would require an extensive amount of financial resources, labour, and risk several contingency costs. Additionally, it would be a disruptive modification, as tenants would not have a functioning kitchen for an estimated three to six weeks. Due to the challenges of modifying the kitchen, this room has not been priced out in detail, and it is noted that the benefits of the modification do not outweigh the costs, thus, it is not feasible to implement.

Although safer flooring materials (vinyl and/or linoleum) and accessible kitchen design elements are not feasible modifications for existing units within the portfolio, it is recommended that all new developments within the TCHC portfolio such as Lawrence Heights and Alexandra Park, should incorporate these elements and modifications in the initial plans to promote accessibility. 


\section{Advanced Modifications}

There are several other modifications that are considered to be important for aging-inplace, however they are not as physically and financially feasible. Elevators and/or lifts for second and third floor access in houses are believed to be vital additions to dwellings, but have the largest financial burden (Bookman, 2008; Smith, 1995 ; Kose, 1997; Fisher et al., 1999). Further modernization of equipment and technology such as intercom communication systems, emergency alarm systems, and activity sensors in the toilet, are considered to be assets to add to units and dwellings to further promote safety in the aging-in-place process, however they are highly priced (Kose, 1997). These modifications will not be proposed to TCHC as they require extensive financial and staff resources to implement and monitor these modifications. 


\section{Structure Types to Modify}

As illustrated, there are a variety of modifications that can be applied to the various TCHC dwellings. However, due to limited funding available, it is important to outline the best proactive, yet cost effective plan regarding how to modify the TCHC portfolio. As previously highlighted, the literature notes that generally, housing stock has not been designed for, or constructed to accommodate for the needs of aging tenants (Tanner \& Tilse, 2008). The TCHC portfolio contains 58,500 units of housing across the City of Toronto, with approximately 45,000 located in high, mid, and low-rise buildings, 11,000 in walk-ups and townhouses, and the remaining in scattered stand-alone housing units (TCHC, 2012c). Due to the extensive number of units, it is not physically and financially feasible to modify each and every one of them. Therefore, the physical criteria for deciding what type of structures to modify are based on current TCHC plans for its buildings, structure typology, and age.

The priority for modifications should be given to the 66 seniors designated buildings within the current portfolio due to the ease of determining which units need to be modified. As these buildings legally only house tenants 59 years old and over, it is easier to assess the needs of the tenants and provide them with the necessary modifications. This allows for the entire building to be retrofitted and guarantees that the modifications will continue to meet the needs of the tenants as, the units will continue to be occupied by seniors. After the 66 seniors designated buildings are modified to physically meet the needs of all the tenants, then the rest of the housing portfolio will be examined based on the following criteria: current TCHC plans, typology, and age. This will help determine which buildings should be selected as appropriate buildings and units within the portfolio to be adapted with agingin-place appropriate modifications.

\section{Current TCHC Plans}

Prior to deciding where to implement the variety of suggested modifications detailed, it is crucial to discuss the current plans that TCHC has according to their portfolio. This is important as it ensures that the plans are physically and financially efficient. TCHC has identified a capital repair backlog of \$751-million, and it has been estimated that it will grow by $\$ 100$-million per year (TCHC, 2011). In order to address this, a revenue solution 
has been proposed, that will allow for the maintenance needs of tenants to be met. The plan is to sell stand-alone houses that have been deemed as expensive and difficult to maintain (TCHC, 2011). The types of stand-alone housing identified for sale are single houses, property houses, and housing in the Single Housing Opportunity Programme (SHOP). This totals approximately 706 buildings, and as of October 2012, 55 buildings had been approved for sale (Moloney, 2012). Due to the unpredictable future of the stand-alone types of housing within the TCHC portfolio, they should not be modified as of yet. Furthermore, developments that have been revitalized and/or newly constructed, including units within Regent Park, are not proposed for modification, as it is assumed that due to the age of the dwellings, the units will include more elements of universal design. However, developments that are currently in the planning stages of revitalization and new construction such as Lawrence Heights, Alexandra Park, Don Mount Court/Rivertowne, Allenbury Gardens, Leslie Nymark, Railway Lands and the West Don Lands, should be developed with aging-in-place in mind (TCHC, 2012d). Rather than having to modify these units in the near future, they should be built and laid out with universal design elements such as lighting, flooring materials, and accessible kitchens and bathrooms. Developing these units with aging-in-place in mind will allow for a proactive plan to be implemented in these buildings.

\section{Building Typology}

With the elimination of the majority of stand-alone homes, the types of dwellings within the portfolio that should be considered are walk-up homes and townhouses, and low, mid, and high-rise apartment buildings. Although the majority of stand-alone buildings are targeted for sale, purpose-built units, units that are part of larger developments, and rooming houses are not, these, therefore require evaluation in regard to modification. There are approximately 168 buildings within this category (TCHC, 2011). It has been determined that two and three storey houses are not deemed to be suitable dwellings for aging-in-place, and require additional adaptations to make them safe and meet the physical needs of aging tenants (Fisher et al., 1999). This is because of their multi-floor layout, stairs to enter the dwelling, and bathrooms that are typically located on second floors (Fisher et al., 1999). This type of building has also been noted to require expensive adaptations 
including lifts and installation of bathrooms on the main level. Smaller scale modifications could be implemented within these dwellings, such as the installation of grab rails. However due to the large-scale investment that would be required, modification is not necessarily as feasible or efficient for walk-up homes and townhouses within the TCHC portfolio.

Units within apartment buildings have been recognized as more practical and easier to modify due to smaller maintained spaces that typically required less adaptations (Fisher et al., 1999). Due to apartment units being arranged on one floor, fewer major costly adaptations are required, such as leveling floors, extensive layout reorganization, and installing ramps and lifts (Kose, 1997). Importantly, they traditionally follow an open concept layout, and include fewer rooms and doorways, allowing for increased accessibility (Fisher et al., 1999). Therefore, to promote aging-in-place, a variety of the smaller scale modifications previously discussed can be implemented. Furthermore, these buildings house the majority of tenants within the portfolio, suggesting that there is an increased need to aid these tenants.

\section{Building Age}

With a greater understanding of the types of buildings to focus on, the aging infrastructure of buildings must be considered when deciding which buildings to modify. The average age of units in elevatored buildings within the portfolio is 33 years. Low-rise apartment buildings are on average 38 years old, high-rise 30 years old, and mid-rise 29 years old (TCHC, 2012c). This illustrates that the portfolio has aging infrastructure that needs to be updated, renovated, and maintained. The aging infrastructure is on the priority list for maintenance and renovation; therefore while maintaining and updating the units and buildings, modifications that promote aging-in-place should be incorporated in the normal course of maintenance. Based on age, it is recommended that the older buildings such as low-rise apartments be a priority for modification.

\section{Buildings to Modify}

Using the aforementioned criteria to determine the buildings within the portfolio to target for modifications, the following building types have been selected and deemed favourable 
for modifications. The buildings that should have priority are the 66 senior designated buildings, which would affect approximately 14,560 tenants (56\% of TCHC senior tenants). This would serve just over half of the current senior tenants. The low-, mid- and high-rise buildings within the current portfolio that meet the aforementioned structure criteria should be the next priority. These are deemed most appropriate due to current physical elements and features, and can correspond to the current TCHC plans and maintenance needs. 


\section{Modification Process}

With a greater understanding of the modifications available, and the buildings and units that should be modified, it is important to outline how tenants and TCHC could adapt the units, and what the process could be. Using the modifications previously discussed, it is important to evaluate which ones senior tenants potentially would be responsible for, and which would be TCHC's responsibility.

\section{Tenant Policy Framework}

While examining the TCHC Tenant Handbook several regulatory barriers were presented that make it difficult for tenants to address modifications to promote aging-in-place. The first is that according to the TCHC Tenant Handbook, tenants are not allowed to make any permanent changes to their units, including the replacement of flooring material, or the removal of doors or fixtures (TCHC, 2006). Furthermore, tenants are not allowed to cause any permanent damage to their walls, including drilling or nailing anything into them, or permanently modifying or changing wall colours (TCHC, 2006). These regulations prevent tenants from adapting their units to include the aforementioned modifications that would allow them to age-in-place.

In addition to tenants not being able to modify their units, they are not able to transfer units within the TCHC portfolio easily to accommodate for their needs. Tenants can apply to transfer units in order to better accommodate for their needs, however, the waiting lists apply to them, and they are not given priority (TCHC, 2006). This process acts on the basis of "first-come, first-served", and these lists are typically several years long (TCHC, 2006). Since there is no priority given to current TCHC tenants to transfer to units that would promote aging-in-place, such as within the seniors-designated buildings, there is a need to modify their current units. This can help alleviate the demand for transfers, and allow for tenants to truly age in their current homes.

\section{Provincial, Municipal and TCHC Policy Framework}

Since tenants are unable to change their units to help them stay safe and foster accessibility in their own homes, there is a need for TCHC to provide these modifications for tenants, or to alter the tenant agreement to allow them to adapt their unit as they see fit for aging-in- 
place. These examples illustrate barriers to supportive living arrangements, and TCHC should play both a positive and proactive role in ensuring that those within their portfolio are not put in compromised safety positions solely based on limiting regulations. As previously discussed, TCHC has the responsibility to act as a responsible and legally compliant landlord and to provide its tenants with healthy and supportive communities. Furthermore, it must comply with the Human Rights Code, City of Toronto Accessibility Plan, and the TCHC Human Rights, Harassment and Fair Access Policy.

At the Provincial level, the Ontario Human Rights Code (Code) notes that inclusive design is a basic human right protected by the legislation. The Code guarantees equal rights and opportunities for all people without discrimination in specific areas, including housing. As section 2 of the Code details,

Every person has a right to equal treatment with respect to the occupancy of accommodation, without discrimination because of race, ancestry, place of origin, colour, ethnic origin, citizenship, creed, sex, sexual orientation, gender identity, gender expression, age, marital status, family status, disability or the receipt of public assistance.

- Human Rights Code, R.S.O. 1990, Chapter H.19, at s. 2(1).

Thus, pursuant to the Code, housing providers have a duty to accommodate tenants, and the failure to do so could result in human rights and discrimination claims being filed based on one of the enumerated grounds, specifically based on age and/or disability (Human Rights Code, 1990). Accordingly, a TCHC landlord would have to provide physical modifications and/or allow for tenants to transfer to other comparable yet modified units. The exception to this is if the modifications and/or accommodations impose undue hardship (including financial) on TCHC (Ontario Human Rights Commission, 2013). However, this is noted to be a very high threshold. In order for a landlord to be able to not accommodate seniors in TCHC buildings, the hardship would have to be so substantial that making the appropriate alterations would either significantly alter the nature of the enterprise, or substantially affect a project's viability (Ontario Human Rights Commission, 
2013). Therefore it is imperative that TCHC take an active role in planning and designing its units to accommodate for the changing physical needs of tenants.

In 2005, the Province of Ontario enacted Accessibility Ontarians with Disability Act (AODA), which provides a province-wide framework outlining mandatory standards for accessibility, affecting all areas of daily life (Accessibility for Ontarians with Disability Act, 2005). Although it does not objectively highlight housing and accommodation as one of its five accessibility areas, it does highlight public spaces, and acknowledges the need for accessible standards (Accessibility for Ontarians with Disability Act, 2005). This would include building entrances and exits and recreational space. The Ontario Building Code helps fill the gap in terms of accessible housing and accommodations. It identifies certain standards and accessibility needs that should be addressed such as wider public corridors and wider doors (Ministry of Municipal Affairs and Housing, 2006). However, only new construction must comply.

Under AODA, the City of Toronto has an Accessibility Plan (City of Toronto Accessibility Plan). The plan outlines a local framework, direction and commitments that will strive to ensure that the City of Toronto is committed to accessibility in various realms such as its programs, services, and facilities (City of Toronto, 2011).

In 2004, TCHC approved an Accessibility Policy for Tenants with Disabilities. In 2007, TCHC through their Community Management Plan continued to identify that social inclusion was key to the organization and its tenants (TCHC, 2007). As a result, the TCHC Accessibility Plan was developed, and sought to promote accessibility, and align and conform with the aforementioned Provincial and Municipal policies. With these policies in place, TCHC invested approximately $\$ 4$ million (from 2004 to 2007) to make TCHC common spaces universally accessible (TCHC, 2007). It also touched upon modifying tenant units, however TCHC acknowledged that only a limited number of units were able to be adapted (TCHC, 2007). The Accessibility Plan highlights that between $2007-2009, \$ 250,000$ per year was allocated to modifying and retrofitting units to create accessible ones (TCHC, 2007). This plan created by TCHC highlights that the organization acknowledges the need for a robust 
accessibility framework, and understands how to be a responsible, effective and legally compliant landlord. However, there does not appear to be an updated plan and financial strategy on how to achieve this past 2009.

\section{Modification Responsibility}

Based on this, it is important to highlight what the senior tenant as opposed to TCHC are respectively responsible for. Although both tenants and TCHC are on very fixed incomes and budgets, the burden of the costs should go to TCHC. As previously illustrated by Figure 1 , senior tenants in Toronto have significantly low incomes, which can make it a struggle to make ends meet and afford the necessities of life. Based on the current policies in place, and the responsibilities of both tenants and TCHC, tenants would be responsible for any modifications that do not require physical changes to the unit, and TCHC would be responsible for larger scale modifications that would require installation. The following chart groups the modifications based on who is financially responsible.

Table 2: Tenant and TCHC Modification Responsibilities

\begin{tabular}{|l|c|c|}
\hline \multicolumn{1}{|c|}{ Modification } & Tenant & TCHC \\
\hline Lever Door Handles & & $\mathrm{X}$ \\
\hline Swing Clear Door Hinge & & $\mathrm{X}$ \\
\hline New Lighting Fixtures & $\mathrm{X}$ & \\
\hline Fluorescent Light Tubes & $\mathrm{X}$ & \\
\hline Fluorescent Light Bulbs & & $\mathrm{X}$ \\
\hline Sensor Light Switches & $\mathrm{X}$ & \\
\hline Night Lights & $\mathrm{X}$ & $\mathrm{X}$ \\
\hline Toilet Seat Cover & & \\
\hline Accessible Bathtub & $\mathrm{X}$ & \\
\hline Bath Seat & $\mathrm{X}$ & \\
\hline Clamp On Bath Rail & & \\
\hline
\end{tabular}




\begin{tabular}{|l|l|c|}
\hline Grab Bars & & $\mathrm{X}$ \\
\hline Fold Down Wall Rail & & $\mathrm{X}$ \\
\hline
\end{tabular}

As the chart above illustrates, the senior tenant and TCHC are each responsible for a variety of modifications, however it is important to note the financial implications and scale of each modification, as some of the highlighted modifications create a greater financial burden than others. 


\section{Financial Implementation}

With a greater understanding of the variety and scale of aging-in-place modifications, a vital component is examining the costs, financial responsibility, and impact of creating barrier free physical environments and dwellings that are made safer and more livable for seniors (Kose, 1997; Fisher et al., 1999). Based on the information gathered from the literature and through informative meetings and modification assessments with professionals, the following modification scenarios have been created. Each modification has been priced based on the modification categories previously discussed, and the costs have been further broken down based on financial responsibility (tenant or TCHC). All of the modifications and the prices per unit are outlined in greater detail in Appendix B.

\section{Modification Cost Scenarios}

Due to the limited financial resources that TCHC has, only modifications that can be deemed feasible while promoting accessible and safe aging-in-place will be discussed. The aim of these cost scenarios is to highlight and outline appropriate modifications that promote units that are adequate for tenants to age-in-place, while being financially feasible.

In order to accommodate all senior tenants, the cost of smaller scale modifications will be examined in more detail. These cost scenarios aim to enhance the units for as many current and future seniors as possible within the TCHC portfolio. As previously mentioned in the Methodology Section, these prices provide estimates of the modification based on research conducted. Due to the scale of these modifications, there are several costs that could not be included such as labour costs, bulk costs, and contingency costs. The modifications discussed require varying levels of labour, and may require a variety of specialists including, but not limited to, contractors, electricians, and plumbers. Accordingly, the costs identified represent the approximate cost of each modification absent the listed exceptions. 
Table 3: General Modifications Moderate Cost Scenario

\begin{tabular}{|c|c|}
\hline \multicolumn{2}{|c|}{ Moderate Scenario } \\
\hline Modification & Estimated Cost \\
\hline \multicolumn{2}{|l|}{ Tenant } \\
\hline $\begin{array}{l}\text { Fluorescent Light Tubes ( } 2 \text { per pack) } \times 3 \\
\text { ( } 2 \text { per Fixture, } 3 \text { Fixtures }- \text { Hallway, Kitchen, } \\
\text { Bathroom) }\end{array}$ & $\$ 25.47$ \\
\hline $\begin{array}{l}\text { Night Lights x } 3 \text { - Sensor Light } \\
\text { (Hallway, Bathroom and Bedroom) }\end{array}$ & $\$ 20.97$ \\
\hline \multicolumn{2}{|l|}{ TCHC } \\
\hline Lever Door Handle - Exterior & $\$ 68.92$ \\
\hline $\begin{array}{l}\text { Lever Door Handle - Interior x } 2 \\
\text { (Bathroom and Bedroom) }\end{array}$ & $\$ 51.94$ \\
\hline $\begin{array}{l}\text { Swing Clear Door Hinge } \mathrm{x} 9 \\
\text { ( } 3 \text { per Door - Exterior, Bathroom, and } \\
\text { Bedroom) }\end{array}$ & $\$ 40.32$ \\
\hline $\begin{array}{l}\text { New Lighting Fixtures x } 3 \\
\text { (Hallway, Bathroom, Kitchen) }\end{array}$ & $\$ 80.88$ \\
\hline $\begin{array}{l}\text { Occupancy Sensor Light Switches x } 4 \\
\text { (Hallway, Kitchen, Bathroom, Bedroom) }\end{array}$ & $\$ 79.88$ \\
\hline Total & $\$ 368.38$ \\
\hline Cost for Tenant & $\$ 46.44$ \\
\hline Cost for TCHC & $\$ 321.94$ \\
\hline
\end{tabular}

This scenario in Table 3 above presents a variety of the general modifications previously discussed which could be applied to the entire unit. These could provide increased accessibility, and help accommodate for tenant limitations such as arthritis and joint conditions. This moderate scenario provides an illustration of the costs for various modifications which the tenant and TCHC would be responsible for. For this scenario, TCHC would have the burden of the cost, and the tenant would have minimal costs. Furthermore, the costs that the tenant would be responsible for would not be considerably different from what they likely already pay for such as light bulbs. The most costly addition would be 
night-lights, which have a long lifespan, and would be considered an investment by the tenant.

Table 4: General Modifications Minimum Cost Scenario

\begin{tabular}{|c|c|}
\hline \multicolumn{2}{|c|}{ Minimum Scenario } \\
\hline Modification & Approximate Cost \\
\hline \multicolumn{2}{|l|}{ Tenant } \\
\hline $\begin{array}{l}\text { Fluorescent Light Tubes ( } 2 \text { per pack) x } 2 \\
\text { ( } 2 \text { per Fixture, } 2 \text { Fixtures -Kitchen, } \\
\text { Bathroom) }\end{array}$ & $\$ 16.98$ \\
\hline $\begin{array}{l}\text { Night Lights x } 3 \text { - LED Non Sensor } \\
\text { (Hallway, Bathroom and Bedroom) }\end{array}$ & $\$ 14.97$ \\
\hline \multicolumn{2}{|l|}{ TCHC } \\
\hline Lever Door Handle - Exterior & $\$ 68.92$ \\
\hline $\begin{array}{l}\text { Lever Door Handle - Interior x } 2 \\
\text { (Bathroom and Bedroom) }\end{array}$ & $\$ 51.94$ \\
\hline $\begin{array}{l}\text { Swing Clear Door Hinge } x 3 \\
\text { (3 per Door - Exterior) }\end{array}$ & $\$ 13.44$ \\
\hline $\begin{array}{l}\text { New Lighting Fixtures x } 2 \\
\text { (Bathroom, Kitchen) }\end{array}$ & $\$ 53.92$ \\
\hline $\begin{array}{l}\text { Occupancy Sensor Light Switches x } 3 \\
\text { (Hallway, Bedroom, Bathroom) }\end{array}$ & $\$ 59.91$ \\
\hline Total & $\$ 280.08$ \\
\hline Cost for Tenant & $\$ 31.95$ \\
\hline Cost for TCHC & $\$ 248.13$ \\
\hline
\end{tabular}

The minimal scenario detailed in Table 4 does not present a drastic difference compared to the moderate scenario. It provides the same modifications, however at a decreased quantity, such as fewer door conversions and lighting fixtures. As illustrated in more detail in Appendix B, the per unit cost of the majority of the modifications in both the minimal and moderate scenarios is low, and therefore TCHC and tenants can determine which modifications would be appropriate to meet their needs. 


\section{Bathroom}

Since bathrooms have been identified as presenting a variety of accessibility challenges and potential hazards, their modification is a key scenario to identify and discuss. Although bathrooms require several key modifications, it is recognized that these modifications are costly. In order to highlight the scale of modifications and the varying costs, three scenarios have been created and analyzed.

Table 5: Bathroom Modifications Premium Cost Scenario

\begin{tabular}{|l|r|}
\hline \multicolumn{2}{|c|}{ Premium Scenario } \\
\hline Modification & Approximate Cost \\
\hline Security Pole with Grab Curve Bar & $\$ 219.99$ \\
\hline Toilet Seat with Handles & $\$ 57.99$ \\
\hline TCHC & $\$ 3,977.00$ \\
\hline Bathtub Replacement with Accessories & $\$ 24.99$ \\
\hline Grab Bar 12" & $\$ 27.99$ \\
\hline Grab Bar 18" & $\$ 209.99$ \\
\hline Fold Down Wall Rail & $\mathbf{\$ 4 , 5 1 7 . 9 5}$ \\
\hline \multicolumn{2}{|c|}{} \\
\hline Total & $\mathbf{\$ 2 7 7 . 9 8}$ \\
\hline Cost for Tenant & $\mathbf{\$ 4 , 2 5 9 . 9 7}$ \\
\hline Cost for TCHC
\end{tabular}

These modifications would create a significant burden on both the senior tenant and TCHC. This scenario in Table 5 is not deemed appropriate for TCHC due to the costs, and should not be seriously considered, however, it provides an illustration of how extensive modifications can be. These types of modifications and design elements are those typically found in purpose built units such as luxury private retirement homes. 
Table 6: Bathroom Modifications Moderate Cost Scenario

\begin{tabular}{|l|r|}
\hline \multicolumn{2}{|c|}{ Moderate Scenario } \\
\hline Modification & Approximate Cost \\
\hline Tenant & $\$ 89.99$ \\
\hline Folding Bath Seat & $\$ 55.69$ \\
\hline Clamp On Bath Safety Rail & $\$ 57.99$ \\
\hline Toilet Seat with Handles & \\
\hline TCHC & $\$ 3,015.40$ \\
\hline Bathtub Replacement without Accessories & $\$ 53.98$ \\
\hline Grab Bar 12" & $\$ 27.99$ \\
\hline Grab Bar 16" x 2 & $\$ 28.99$ \\
\hline Grab Bar 18" & \\
\hline Grab Bar 24" & $\mathbf{\$ 3 , 3 5 3 . 0 2}$ \\
\hline & $\mathbf{1 1 3 . 6 8}$ \\
\hline Total & $\mathbf{3 , 2 3 9 . 3 4}$ \\
\hline Cost for Tenant & \\
\hline Cost for TCHC & \\
\hline
\end{tabular}

As bathrooms have been noted as common spaces where accidents occur, it is important to outline the costs of bathtub replacements. In order to decrease the cost of the bathtub replacements, tubs can be purchased without the accessories such as grab bars. The moderate scenario detailed in Table 6 outlines this replacement without the accessories, as well as the installation of grab bars in necessary locations such as near the toilet and within the bathtub replacement. A clamp on bath safety rails and toilet seat inserts have been included in this scenario as they promote bathroom safety at a moderate cost.

Although a bathtub replacement is seen as a necessary modification as it removes a significant hazard, it is costly and challenging, and is therefore deemed unfeasible. This large-scale modification is expensive, requires intensive labour, and has the potential to 
significantly disrupt the tenant. Due to the number of units that are within the portfolio that currently have or will have a senior tenant, bathtub replacements are not feasible.

Table 7: Bathroom Modifications Minimum Cost Scenario

\begin{tabular}{|l|r|}
\hline \multicolumn{2}{|c|}{ Minimum Scenario } \\
\hline Modification & Approximate Cost \\
\hline Tenant & $\$ 55.69$ \\
\hline Clamp On Bath Safety Rail & $\$ 44.99$ \\
\hline Bath Seat with No Back & $\$ 55.99$ \\
\hline Toilet Seat with No Handles & \\
\hline TCHC & $\$ 24.99$ \\
\hline Grab Bar 12" & $\$ 80.97$ \\
\hline Grab Bar 16" x & $\$ 27.99$ \\
\hline Grab Bar 18" & $\$ 28.99$ \\
\hline Grab Bar 24" & \\
\hline & $\$ 285.61$ \\
\hline Total & $\$ 156.67$ \\
\hline Cost for Tenant & $\$ 128.94$ \\
\hline Cost for TCHC & \\
\hline
\end{tabular}

This scenario presents the most feasible alternative to fully modifying the bathrooms within the portfolio as they are significantly less costly and disruptive than the other two scenarios have illustrated. The minimal scenario in Table 7 will aid in improving the units for a more significant number of tenants. Following this scenario, approximately twentyfive units can be modified by TCHC at the same cost as one unit at the price outlined in scenario two (Table 6). Although the bathtub is not being retrofitted, this scenario presents several modifications which could enhance the space for safer use. In order to prevent falls in the bathtub, a bath seat should be placed in the tub, and a clamp on bath safety rail should be positioned on the edge to create greater ease when entering and exiting the tub. Additionally, grab bars should be placed within the existing bathtub walls to help with 
stability, and around the toilet. These modifications all illustrate various elements which can aid in improving safety and the capability to age-in-place within the existing units, while being cost effective. Furthermore, this scenario presents a total cost which is more feasible, resulting in the possibility of additional units being modified. This will help modify as many units as possible, resulting in the maximum number of seniors being served.

A barrier seen within this scenario is the shift from TCHC responsibility to that of the tenant. As the previous scenarios illustrated, the burden of the costs fell on TCHC, however this scenario highlights a shift in responsibility and burden. This is not an ideal situation, however due to the diminished cost for TCHC, it would enable the corporation to modify a greater number of senior units with vital improvements that will promote aging-in-place.

\section{Impact on TCHC Budget}

Table 8 below illustrates the total cost of modifications for the general and bathroom modifications, and includes the total costs that TCHC would be responsible for using the aforementioned minimum scenarios. It represents the total cost per unit.

Table 8: Cost Summary for TCHC Modifications Using Minimum Scenarios

\begin{tabular}{|c|c|}
\hline Modification & Approximate Cost \\
\hline \multicolumn{2}{|l|}{ General } \\
\hline Lever Door Handle - Exterior & $\$ 68.92$ \\
\hline $\begin{array}{l}\text { Lever Door Handle - Interior x } 2 \\
\text { (Bathroom and Bedroom) }\end{array}$ & $\$ 51.94$ \\
\hline $\begin{array}{l}\text { Swing Clear Door Hinge x } 3 \\
\text { (3 per Door - Exterior) }\end{array}$ & $\$ 13.44$ \\
\hline $\begin{array}{l}\text { New Lighting Fixtures x } 2 \\
\text { (Bathroom, Kitchen) }\end{array}$ & $\$ 53.92$ \\
\hline $\begin{array}{l}\text { Occupancy Senior Light Switches x } 3 \\
\text { (Hallway, Bedroom, Bathroom) }\end{array}$ & $\$ 59.91$ \\
\hline \multicolumn{2}{|l|}{ Bathroom } \\
\hline Grab Bar 12" & $\$ 24.99$ \\
\hline
\end{tabular}




\begin{tabular}{|l|l|}
\hline Modification & Approximate Cost \\
\hline Grab Bar 16" x 3 & $\$ 80.97$ \\
\hline Grab Bar 18" & $\$ 27.99$ \\
\hline Grab Bar 24" & $\$ 28.99$ \\
\hline & \\
Total & $\mathbf{\$ 4 1 1 . 0 7}$ \\
\hline
\end{tabular}

As illustrated, the modifications without labour and any contingency costs would cost TCHC $\$ 411.00$ per unit modified. As previously discussed, TCHC allocated $\$ 250,000$ per year over three years for creating accessible units and retrofits (TCHC, 2007). If TCHC were to apply the aforementioned minimal modification scenario with the $\$ 750,000$ budget over three years, an estimated 1,825 units could be modified. This is based on only the cost per unit, and unfortunately does not include labour and contingency costs associated with these accessible modifications. However, provides a greater indication of the amount of modifications that can be made based on existing accessible budgets outlined by TCHC.

The major cost considerations for these modifications that must be factored into their feasibility are both hard and soft costs. As previously discussed, due to the average age of TCHC's buildings, there is already a high demand for maintenance present, and the backlog has doubled from $\$ 322$ million in 2006 to $\$ 650$ million in 2011 (TCHC, 2011). This backlog is expected to grow due to limited sources of revenue, and the absence of a revenue surplus. (TCHC, 2011).

Despite the fact that these modifications are expensive, the costs have been considered to be a less expensive strategy to house aging tenants, compared to building new seniors designated developments (Fisher et al., 1999). The City of Toronto Affordable Housing Office highlights from a municipal government perspective, housing a senior in a city run long-term care home can cost approximately $\$ 56,000$ per year. However, retrofitting a home to encompass aging-in-place elements costs a fifth of this price (City of Toronto, 2012b). The modifications and investments to units are pertinent to promoting aging-in- 
place, and are becoming additionally more important as a large portion of TCHC tenants age over the next decades.

\section{Examples of Funding Programs Currently Available}

There are several financial programs and sources that have been established and could be used in order to help fund these modifications. At the federal level, there is the Residential Rehabilitation Assistance Program (RRAP), which is run by the federal government, and provides financial assistance for the purpose of modifying housing to meet health and safety standards $\left(\mathrm{CMHC}_{2}, 2012\right)$. The March of Dimes Home and Vehicle Modifications Program is established by and administered on behalf of the Government of Ontario Ministry of Community and Social Services, which provides funding for home modifications up to $\$ 15,000$ (March of Dimes, 2011). Recipients of this grant can use it for modifications such as widening doors, and rearranging kitchens and/or washrooms (March of Dimes, 2011). Lastly, at the local level, there is Toronto Renovates, a new program that was expected to commence in Spring 2013 through the City of Toronto's Affordable Housing Office. This program will strive to provide assistance to lower-income homeowners who require funding for essential health and safety repairs (Affordable Housing Office, 2013). There is a limited amount of funding available for seniors and disabled persons, therefore the eligibility for this grant is that the assessed value of the home is less than $\$ 514,000$, and meets income thresholds. This will help fund essential repairs and modifications that enable seniors to live independently (Affordable Housing Office, 2013). There is also a Healthy Home Renovation Tax Credit which is a tax credit which allows for a portion of the accessible renovations (up to $\$ 1,500$ ) to be covered by the Province of Ontario (Government of Ontario, 2013).

These are four examples of public and not-for profit resources available for home modifications and home repair assistance, however TCHC tenants are not able to apply to them since these grants are only for dwellings that are owned by the applicant, and TCHC tenants are not able to legally modify their units. However, these types of grants provide a precedent for what the City of Toronto and TCHC can establish for aging tenants to enhance the feasibility of modifying units to meet their needs. 


\section{Imperative}

With a greater understanding of the current condition within units for the aging tenancy of TCHC, the policies, and the costs and financial implications of implementing the modifications, it is necessary to stress the imperative of proactively planning. There is an imperative for the tenant and TCHC to start to modify the home, in addition to there being an imperative for higher levels of government such as the City of Toronto and Province of Ontario to help keep senior tenants safe and out of long-term care settings.

\section{Tenant Imperative}

The success of modifying units relies on a partnership between the tenants and TCHC. The tenants would have a responsibility to purchase modifications that would help their homes be safe and foster aging-in-place. Using the minimum scenarios, tenants would be responsible for paying an estimated $\$ 32.00$ for general modifications, and $\$ 156.00$ for bathroom modifications. This presents a problem, as these costs would have an onerous impact on the already constrained and limited disposable incomes of tenants. As illustrated by Figure 1, senior renters have very tight incomes, leaving little disposable income, which is often necessary to spend on items such as food and medications. Since these tenants are most likely not in the workforce anymore, these modification costs are most likely unfeasible for them.

Even though the costs of the modifications presents a barrier to tenants, they are essential to implement as older cohorts are most likely to have conditions that limit their daily activities and an unmodified unit can continue to contain challenges and pose threats to the tenants health and safety. Therefore, it is essential to educate tenants on how these modifications can help accommodate for the loss of skills essential to completing the basic activities of daily living such as toileting and bathing. As outlined, there are several modifications that can be added to their units which tenants can provide themselves such as nightlights and bath seats that can enhance their ability to complete daily tasks safely, and help prevent falls, ultimately keeping them safe and deferring the need for long-term care settings. 
Although the costs are high, tenants should be educated and aware of what is needed to keep them safe, and realize that they may not require all the modifications discussed. When evaluating their own needs, they can use unit audit checklists such as the one illustrated by Table 1. Tenants can determine what levels of modifications are needed for their units while reflecting their limited budget. Implementing modifications can be flexible and not all of the modifications discussed need to be implemented in order to foster accessibility and safety. However, there is a need to modify based on the tenants needs and their current barriers within their units, while reflecting their limited budget. Due to the large amount of senior tenants and aging tenants, it is important to advocate for these modifications to be made, and even if it motivates a fraction of tenants to take initiative and provide themselves with modifications, it is a proactive step in the right direction.

\section{TCHC Imperative}

TCHC should recognize the changing demographics within all of its portfolio buildings, and should accommodate the needs of tenants as best it can. It is conceded that accommodating each and every need of all tenants, in particular seniors, would not only be a significant financial burden on the organization, but on a practical level is likely not feasible. However, TCHC nonetheless has an obligation to accommodate tenants up until the point of undue hardship. The Ontario Human Rights Code recognizes the dignity and worth of each and every Ontarian, and promotes fostering understanding and mutual respect. TCHC is legally bound by the Code which specifically protects individuals against discrimination based on age and disability. Therefore, if unit modifications are not done, this lack of action could be deemed discriminatory, as the safety needs of elderly and perhaps disabled tenants would not be met. Additionally, if tenants are not able to continue to live in their units and age-in-place, this could undermine their sense of dignity and could reinforce their vulnerability in society. The imperative for TCHC to assist in the modification of units lies in their obligation to ensure that equality is fostered for each and every tenant in their portfolio by ensuring that buildings and units are as accessible and livable as possible. In the context of seniors designated buildings and units that seniors live in, arguably this requires that seniors be accommodated through modifications to various unit elements, especially the 
additional safety enhancing components. Because the chances of living with chronic illness or disability increases as individuals age, the prevalence of illness and disability is greater among seniors relative to the general population. Accordingly, TCHC should pay particular attention to the units where seniors live, and recognize that the modification and accommodation needs differ from other units in their portfolio.

\section{Government Imperative}

There is also a need to expand the imperative to a broader scope, and get municipal and provincial involvement in providing TCHC tenants with safer and accessible units. This will help alleviate stress on the strained health care and long-term care home systems. In 2011 - 2012, an estimated 68,037 older Ontarians were provided care through the assisted living and supportive housing programs, provided primarily through Community Care Access Centres (CCAC) (Sinha, 2012). CCAC agencies provide a variety of programs and services such as personal support, essential homemaking services, and regularly scheduled emergency care needs (Sinha, 2012). In 2012, the average cost per day of the care provided by CCACs was $\$ 56.21$, which translates to $\$ 10,716$ annually (Sinha, 2012).

Without programs and services such as alternative assisted living and supportive housing options, it has been noted that the Province of Ontario will need to triple the current supply of long-term care beds to meet the predicted demand for long-term care over the next two decades. The annual provincial subsidy for long-term care is $\$ 47,940$ (Sinha, 2012).

Seniors require personal support and long-term care as they begin to be unable to support themselves, which can be due to barriers and challenges within their units. Furthermore, many seniors are forced to enter long-term care settings after severe injuries occur as a result of a fall in their homes (Sinha, 2012). Home modifications have been seen to provide more options for seniors to age-in-place, and not forcing them to prematurely be admitted to long-term care homes (Sinha, 2012).

Given these costs, the estimated $\$ 415$ to modify current units and help seniors remain in their current TCHC units would greatly help alleviate the burden on the health care system 
as daily limitations would not be challenged. The modifications discussed are seen to act as preventative measures to keep seniors out of care settings. This will allow more people to remain independent and age in the place of their choice rather than facilitate more costly and less desirable entry into long-term care. There is incentive for the municipal and provincial government to provide resources to TCHC to help this vulnerable group, and prolong them from entering into assisted care settings such as long-term care homes and hospitals. 


\section{How to Get There?}

It must be acknowledged again that only the physical component of aging-in-place has been examined through this research, which represents just one small aspect of aging-in-place. As previously mentioned, the 2008 TCHC Seniors Implementation Framework outlined four key pillars within their strategy: (1) buildings; (2) health and wellbeing, (3) community engagement; (4) culture of change and continuous learning ( $\left.\mathrm{TCHC}_{1}, 2012\right)$. In order to foster and promote aging-in-place, all the pillars must continue to be examined and addressed. Based on the research and findings related to modifying TCHC units, and due to the importance of modifying them to promote and accommodate aging-in-place, the following recommendations have stemmed from this research.

\section{Modification Recommendations}

TCHC should implement 'quick win' modifications.

- As illustrated in this research, there are several modifications that can promote safe aging-in-place for senior tenants, however in order for modifications to be made, it is important to assess the modifications based on the relational impact of aging-inplace and its feasibility. Several of the modifications discussed such as lever door handles and grab rails can be installed relatively easily with minimal costs and maintenance. These adaptations would have a large impact on creating safer units while accommodating for health conditions. Modifications should be prioritized based on financial resources available, ease of maintenance, and impact to tenants.

Create a phasing strategy for modifications

- A phasing strategy should be developed to determine which specific buildings and units within the portfolio should be modified first. The first phase should be modifying senior designated buildings, followed by apartment buildings. Additional criteria should be considered for adaptations. This includes a conducting a more indepth analysis of the tenants within the portfolio, and determining the buildings that have an aging tenancy, which should be targeted for modification. 


\section{Use Existing Programs to Assess and Implement Modifications}

- Currently, TCHC has a system, EasyTrac, in place to address unit maintenance. EasyTrac makes placing and following up on maintenance requests easier by providing tenants with a specific EasyTrac number to follow, and allows all staff, superintendents, and the Response Centre staff to have access to the service database showing the status of each request (TCHC, 2013). This system can incorporate aging-in-place specific modifications and help ensure that seniors needs are being met. This system allows for prioritization to be made within the maintenance and repair request database, and TCHC should think of putting senior specific modifications as a priority.

\section{Educate Tenants on Modification Benefits}

- Aging residents should be educated about the positive impacts that modifications can have on their units, and how they could allow for them to age-in-place safely. Due to the varying ability levels of tenants as they age, there is not one standard set of modifications that will reflect the different needs of tenants. Therefore through public education initiatives, tenants would be in a better position to determine what modifications fit their needs. There is a need to distribute the unit checklist such as the example one illustrated by Table 1 to tenants in order for them to assess what they already have in their units, and what is needed to make their home appropriate for aging-in-place.

\section{Policy Recommendations}

\section{Reevaluate Landlord-Tenant Agreement}

- In order to allow for greater flexibility in terms of modifying units, there should a reevaluation of tenant regulation. The TCHC- tenant agreement should include a clause regarding specific pre-determined modifications that tenants could implement at their own cost to promote accessibility and safety relating to aging within their units and meeting their personal needs. Since tenants are on low and fixed incomes, these modifications can be onerous, and they would be able to apply 
for and use resources such as modification grants rather than personal resources. This could alleviate the pressure on TCHC and the duty to accommodate related to modifying each unit.

Update the 2007 TCHC Accessibility Plan

- In 2007, TCHC created and released an Accessibility Plan outlining how they would create healthy and inclusive communities. This plan outlined how to achieve accessible units through creation of new ones and retrofitting old ones. However, this plan only provided a plan until 2009, and has not been since updated. There is a need to use the existing plans framework as a guide to create a revised and current plan to reflect the current needs of the TCHC portfolio, focusing more on creating accessible units as accessible common areas have already been addressed.

\section{Align with Senior Policies at different levels of Government}

- In 2013, the Province of Ontario and the City of Toronto released Senior Strategies; however at this particular point in time, these strategies have yet to address home modifications within mixed-aged affordable housing. Thus, in order to make these modifications feasible, they must be incorporated at the different levels of government, and within their long-term strategies and budgets. This will aid in ensuring that home modifications to units form a step in a proactive plan to facilitate aging-in-place.

\section{Financial Recommendations}

\section{Update Budget to Reflect Accessibility}

- In 2007, the TCHC Accessibility Plan had a detailed budget on how they would achieve an accessible portfolio. The $\$ 1.5$ million budget was outlined with the Community Management Plan was allocated to accessibility related expenses over three years, and more specifically $\$ 750,000$ towards accessible units. It is important to reexamine this prior TCHC budget, and to establish an updated one to reflect the modifications required throughout the portfolio. 
Finding Financial Resources within the Financial Plans

- As TCHC continues to find alternative revenue resources, there should be a consideration of using a certain percentage of the money it receives to go towards aging-in-place in seniors and non-seniors designated buildings. For example, as the stand-alone housing units get sold to compensate for maintenance costs, a certain percentage of this revenue could go towards modifying units.

\section{Finding Alternative Financial Resources}

- Due to the strained budget which TCHC faces, there is a need to seek out alternative financial resources. TCHC should seek out conditional grants from the Province of Ontario and City of Toronto in order to ensure that the tenant units get modified for the safety of the aging tenants and to ensure that they are able to prolong entering long-term care setting. This can ultimately alleviate pressure on the health care system. The provincial and municipal government should allocate funding for these modifications through the revision of their Seniors Strategies and senior related budgets.

\section{Seek Out Private-Public Partnerships}

- It is important to continue to seek out public-private partnerships in order for modifications to be complete. TCHC has seen success in public-private partnerships through the revitalization of Regent Park with the Daniels Corporation. Therefore it is essential to continue to use external resources and expertise. An example would be to reduce labour and installation costs by getting college students to install the modifications through apprenticeship programs run through the various colleges in Toronto. This provides hands on opportunities for students while being able to modify units at a reduced cost. This may require some changes to the internal TCHC labour agreements. 


\section{Conclusion}

Modifying TCHC units to promote aging-in-place will not be an easy endeavor, however it is fundamental to do. Providing aging TCHC tenants with an opportunity to remain in their housing units and age-in-place is an important component of addressing their housing needs in the decades to come. By implementing and allowing for modifications, physical barriers that may impede their ability to function could be removed, and accessibility and independence could be increased. It is important to realize that a range of cost-effective modification options are available, as is illustrated in this research. However, in order to implement them, several reflective regulations and financial resources will need to be discussed and obtained to foster the adaptations. It is essential to have increased cooperation and coordination amongst both tenants and TCHC as both stakeholders have a responsibility in creating safe units to allow for aging-in-place to occur. TCHC needs to act proactively and take a leadership role in respecting the elders of Toronto, more specifically their tenancy. 


\section{Appendix A}

This guide is intended to provide an indication of where each modification price discussed in detail within the cost scenarios was collected from. Some of these prices were collected in store in Toronto, online, or by phone between January and February 2013.

\begin{tabular}{|l|l|l|}
\hline Modification & Source & $\begin{array}{l}\text { Method (In Store, } \\
\text { Online or by } \\
\text { Phone) }\end{array}$ \\
\hline $\begin{array}{l}\text { General } \\
\text { Philips Fluorescent Light } \\
\text { Tubes (2 per pack)- 32 Watt } \\
\text { T8 48 Inch }\end{array}$ & Home Depot Canada \\
\hline $\begin{array}{l}\text { Good Choice Automatic LED } \\
\text { Night Light - Motion Sensor }\end{array}$ & Home Depot Canada & In Store \\
\hline $\begin{array}{l}\text { Good Choice Crystal LED } \\
\text { Night Light - Non Sensor }\end{array}$ & Home Depot Canada & In Store \\
\hline $\begin{array}{l}\text { Brinks Lever Door Handle - } \\
\text { Exterior }\end{array}$ & Canadian Tire & In Store \\
\hline $\begin{array}{l}\text { Weiser Lock Lever Door } \\
\text { Handle - Interior }\end{array}$ & Home Hardware & In Store \\
\hline $\begin{array}{l}\text { Swing Clear Door Hinge } \\
\text { Pack - 3 Inch }\end{array}$ & Lowes Canada & Online \\
\hline $\begin{array}{l}\text { Lithonia Lighting 4' T8 2L } \\
\text { Fight Switch }\end{array}$ & Home Depot Canada & Online \\
\hline
\end{tabular}




\begin{tabular}{|c|c|c|}
\hline Modification & Source & $\begin{array}{l}\text { Method (In Store, } \\
\text { Online or by } \\
\text { Phone) }\end{array}$ \\
\hline \multicolumn{3}{|l|}{ Bathroom } \\
\hline $\begin{array}{l}\text { Security Pole with Grab Curve } \\
\text { Bar }\end{array}$ & Shoppers Home Health Care & In Store \\
\hline $\begin{array}{l}\text { AquaSense Toilet Seat with } \\
\text { Handles }\end{array}$ & Shoppers Home Health Care & In Store \\
\hline AquaSense Folding Bath Seat & Shoppers Home Health Care & In Store \\
\hline $\begin{array}{l}\text { AquaSense Clamp On Bath } \\
\text { Safety Rail }\end{array}$ & Shoppers Home Health Care & In Store \\
\hline $\begin{array}{l}\text { AquaSense Bath Seat with No } \\
\text { Back }\end{array}$ & Shoppers Home Health Care & In Store \\
\hline $\begin{array}{l}\text { AquaSense Toilet Seat with } \\
\text { No Handles }\end{array}$ & Shoppers Home Health Care & In Store \\
\hline $\begin{array}{l}\text { Bathtub Replacement with } \\
\text { Accessories }\end{array}$ & Barrier Free Architecturals Inc & By Phone \\
\hline $\begin{array}{l}\text { Bathtub Replacement without } \\
\text { Accessories }\end{array}$ & Barrier Free Architecturals Inc & By Phone \\
\hline Grab Bar 12 & Shoppers Home Health Care & In Store \\
\hline Grab Bar 16" & Shoppers Home Health Care & In Store \\
\hline Grab Bar 18" & Shoppers Home Health Care & In Store \\
\hline Grab Bar 24" & Shoppers Home Health Care & In Store \\
\hline Fold Down Wall Rail & Shoppers Home Health Care & In Store \\
\hline
\end{tabular}




\section{Appendix B}

This chart illustrates the price for each modification based on the research conducted. This is a pretax price without labour and any other associated contingency costs. These prices were collected between January and February 2013.

\begin{tabular}{|c|c|c|}
\hline Modification & Price & Source \\
\hline \multicolumn{3}{|l|}{ General } \\
\hline $\begin{array}{l}\text { Philips Fluorescent Light } \\
\text { Tubes (2 per pack)- } 32 \text { Watt } \\
\text { T8 } 48 \text { Inch }\end{array}$ & $\$ 8.49$ & Home Depot Canada \\
\hline $\begin{array}{l}\text { Good Choice Automatic LED } \\
\text { Night Light - Motion Sensor }\end{array}$ & $\$ 6.99$ & Home Depot Canada \\
\hline $\begin{array}{l}\text { Good Choice Crystal LED } \\
\text { Night Light - Non Sensor }\end{array}$ & $\$ 4.99$ & Home Depot Canada \\
\hline $\begin{array}{l}\text { Brinks Lever Door Handle - } \\
\text { Exterior }\end{array}$ & $\$ 68.92$ & Canadian Tire \\
\hline $\begin{array}{l}\text { Weiser Lock Lever Door } \\
\text { Handle - Interior }\end{array}$ & $\$ 25.97$ & Home Hardware \\
\hline $\begin{array}{l}\text { Swing Clear Door Hinge } \\
\text { Stanley-National Hardware 2- } \\
\text { Pack - } 3 \text { Inch }\end{array}$ & $\$ 4.48$ & Lowes Canada \\
\hline $\begin{array}{l}\text { Lithonia Lighting 4' T8 2L } \\
\text { Fluorescent Lighting Fixtures }\end{array}$ & $\$ 26.96$ & Home Depot Canada \\
\hline $\begin{array}{l}\text { Cooper Occupancy Sensor } \\
\text { Light Switch }\end{array}$ & $\$ 19.97$ & Home Hardware Canada \\
\hline
\end{tabular}




\begin{tabular}{|c|c|c|}
\hline Modification & Price & Source \\
\hline \multicolumn{3}{|l|}{ Bathroom } \\
\hline $\begin{array}{l}\text { Security Pole with Grab Curve } \\
\text { Bar }\end{array}$ & $\$ 219.99$ & Shoppers Home Health Care \\
\hline $\begin{array}{l}\text { AquaSense Toilet Seat with } \\
\text { Handles }\end{array}$ & $\$ 57.99$ & Shoppers Home Health Care \\
\hline AquaSense Folding Bath Seat & $\$ 89.99$ & Shoppers Home Health Care \\
\hline $\begin{array}{l}\text { AquaSense Clamp On Bath } \\
\text { Safety Rail }\end{array}$ & $\$ 55.69$ & Shoppers Home Health Care \\
\hline $\begin{array}{l}\text { AquaSense Bath Seat with No } \\
\text { Back }\end{array}$ & $\$ 89.99$ & Shoppers Home Health Care \\
\hline $\begin{array}{l}\text { AquaSense Toilet Seat with } \\
\text { No Handles }\end{array}$ & $\$ 55.99$ & Shoppers Home Health Care \\
\hline $\begin{array}{l}\text { Bathtub Replacement with } \\
\text { Accessories }\end{array}$ & $\$ 3,977.00$ & $\begin{array}{l}\text { Barrier Free Architecturals } \\
\text { Inc }\end{array}$ \\
\hline $\begin{array}{l}\text { Bathtub Replacement without } \\
\text { Accessories }\end{array}$ & $\$ 3,015.40$ & $\begin{array}{l}\text { Barrier Free Architecturals } \\
\text { Inc }\end{array}$ \\
\hline Grab Bar 12 & $\$ 24.99$ & Shoppers Home Health Care \\
\hline Grab Bar 16" & $\$ 26.99$ & Shoppers Home Health Care \\
\hline Grab Bar 18" & $\$ 27.99$ & Shoppers Home Health Care \\
\hline Grab Bar 24" & $\$ 28.99$ & Shoppers Home Health Care \\
\hline Fold Down Wall Rail & $\$ 209.99$ & Shoppers Home Health Care \\
\hline
\end{tabular}




\section{Reference List}

Accessibility for Ontarians with Disabilities Act, S.0. 2005, Chapter 11

Affordable Housing Office . (2013). Assistance for Lower-Income Homeowners (Brochure). Toronto: City of Toronto.

Bakker, R. (1997). Elder Design: Designing and Furnishing A Home for Your Later Years. New York, USA: Penguin Books.

Bookman, A. (2008). Innovative Models of Aging in Place: Transforming Our Communities for an Aging Population. Community, Work \& Family, 11(4), 419-438.

Carbon Free Homes. (2013). Investment in Walkin Bathtubs. Retrieved from http://www.carbonfreehomes.org/why-invest-in-a-walk-in-bathtub/

CareCorner. (2011). Aging Safely at Home: Home Modification. Retrieved from http://carecorner.net/aging-safely-at-home-home-modification

Centers for Disease Control and Prevention (CDC). (2012). Health Places Terminology. Retrieved from http://www.cdc.gov/healthyplaces/terminology.htm

City of Toronto. (2011). Accessibility Guidelines. Retrieved from http://www1.toronto.ca/ wps/portal/toronto/content?vgnextoid $=05043552415 \mathrm{bb} 310$ VgnVCM10000071d 6 0f89RCRD\&vgnextchannel=1affa16d218aa310VgnVCM10000071d60f89RCRD

City of Toronto. (2012). Seniors Strategy Expert Panel Roundtable. Presentation

City of Toronto. (2012b). Investments in Affordable Housing: Proposed Program Allocations for New Federal/Provincial Funding. Retrieved from http://www.toronto.ca/legdocs /mmis/2012/ex/bgrd/backgroundfile-44359.pdf

CMHC. (2012a). Accessible Housing by Design. Retrieved from http://www.cmhcschl.gc.ca/en/co/co_009.cfm

CMHC. (2012b). Ontario Residential Rehabilitation Assistance Program. Retrieved from http://www.cmhc.ca/en/co/prfinas/prfinas_015.cfm

Davey, J. (2006). Ageing in Place: The Views of Older Homeowners on Maintenance, Renovation and Adaptation. Social Policy Journal of New Zealand, 27, 128-141.

Fisher, J., Giloth, R. (1999). Adapting Rowhomes for Aging in Place. Journal of Housing for the Elderly, 13(1-2), 3-18.

Government of Ontario. (2013). Healthy Home Renovation Tax Credit. Retrieved from 
http://www.ontario.ca/taxes-and-benefits/healthy-homes-renovation-tax-credit

Heywood, F. (2001). Housing and Home in Later Life. Philadelphia, PA: Open University Press.

Home Hardware Canada. (2013). Door Handles. Retrieved from http://www.homehardware.ca/en/cat/search/_/N-2pqfZ67l/Ne-67n/NtkAll_EN?Ntt=lever+door+handles

Human Rights Code, R.S.O. 1990, Chapter H.19

Kose, S. (1997). Housing Elderly People in Japan. Ageing International, 148-164.

Littlefield, R. \& McNulty, R. (2012). Independent for Life: Homes and Neighborhoods for an Aging America $\left[1^{\text {st }}\right.$ ed.). Austin: University of Texas Press

Lowes Canada. (2013). Door Hinges. Retrieved from http://www.lowes.ca/doorhinges_694.html?s_kwcid=\%2Blowes\%20\%2Bhinges|18613453336\&gclid=CIvXw8 XGz7YCFXNOMgodDg0AsA\&gclsrc=aw.ds

March of Dimes. (2011). Home \& Vehicle Modification Program. Retrieved from http://www.marchofdimes.ca/EN/programs/hvmp/Pages/HomeandVehicle.aspx

MetLife. (2010). Aging in Place Workbook. Retrieved from https://www.metlife.com/ assets/cao/mmi/publications/studies/2010/mmi-aging-place-workbook.pdf

Michael, Y., Green, M., Farquhar, S. (2006). Neighborhood Design and Active Aging. Health and Place, 12, 734-740.

Ministry of Municipal Affairs and Housing. (2006). Ontario Building Code. Retrieved from http://www.mah.gov.on.ca/Page7393.aspx

Ministry of Municipal Affairs and Housing. (2009). Canada-Ontario Affordable Housing Initiative Social Housing Renovation and Retrofit Program (SHRRP).

Moloney, P. (2012, October 9). Sale of 55 TCHC homes endorsed by Toronto's executive committee. The Toronto Star. Retrieved from http://www.thestar.com/ news/gta/article/1268743--sale-of-55-homes-endorsed-by-toronto-s-executivecommittee

Mynatt, E., Essa, I., Rogers, W. (2000). Increasing the Opportunities for Aging in Place. ACM Guide to Computing Literature, 65-71.

National Association of Home Builders (NAHB). (2005) The National Older Adult Housing Survey. Retrieved from http://www.toolbase.org/PDF/CaseStudies/NOAHSecondaryAnalysis.pdf 
Ontario Human Rights Commission. (2013). Duty to Accommodate. Retrieved from http://www.ohrc.on.ca/en/human-rights-and-rental-housing-ontario-backgroundpaper/duty-accommodate

Priemus, H., Dieleman, F., Clapham, D. (1999). Current Developments in Social Housing Management. Journal of Housing and the Built Environment, 4(3), 211-223.

Pynoos, J., \& Nishita, C. (2003). The Cost and Financing of Home Modifications in the United States. Journal of Disability Policy Studies, 14(2), 68-73.

Sears Canada. (2013). AquaSense Products. Retrieved from http://www.sears.ca/ catalog/aquasense/0-100000469

Sinha, Dr. S. (2012). Living Longer, Living Well. Retrieved from http://www.health.gov.on. $\mathrm{ca}$ /en/common/ministry/publications/reports/seniors_strategy/

Smith, N. (1995). Challenges of Public Housing in the 1990s: The Case of Ontario, Canada. Housing Policy Debate, 6(4), 905-931.

Statistics Canada. (2011). Census in Brief: Living Arrangements of Seniors. 2011 Census of Population.

Taira, E. \& Carlson, J. (1999). Aging in Place: Designing, Adapting, and Enhancing the Home Environment. New York: The Haworth Press.

Tanner, E., Tilse, C., \& de Jonge, D. (2008). Restoring and Sustaining Home: The Impact of Home Modifications on the Meaning of Home for Older People. Journal of Housing for the Elderly, 22(3), 195-215.

TCHC. (2006). Tenant Handbook. Retrieved from http://www.torontohousing.ca/ webfm_send/297/1

TCHC. (2007). Accessibility Plan. Retrieved from http://www.torontohousing.ca/ webfm_send/4367/1

TCHC. (2008). Sustaining Age-Friendly Communities for Senior Tenants. Seniors Implementation Framework. Retrieved from http://www.torontohousing.ca /webfm_send/6536

TCHC. (2011). Stand-alone Units Portfolio. Retrieved from http://www.torontohousing.ca/ webfm_send/7677/1

TCHC. (2012a). 2011 Annual Report. Retrieved from http://www.torontohousing.ca/ webfm_send/8838 
TCHC. (2012b). Seniors. Retrieved from http://www.torontohousing.ca/Seniors

TCHC. (2012c). Frequently Asked Questions. Retrieved from http://www.toronto housing.ca/media_centre/faq

TCHC. (2012d). Investing in Buildings. Retrieved from http://www.torontohousing.ca/ revitalization

TCHC. (2012e). Successful Tenancies. Retrieved from http://www.torontohousing.ca/ successful_tenancies

TCHC. (2013). EasyTrac. Retrieved from http://www.torontohousing.ca/ tenant_life/easytrac

Thiele, B. (2002). The Human Right to Adequate Housing: A Tool for Promoting and Protecting Individual and Community Health. American Journal of Public Health, 92(5), $712-715$.

United Nations. (1996). The Habitat Agenda: Chapter IV: B. Adequate Shelter for All. Retrieved from http://www.un-documents.net/ha-4b.htm

World Health Organization. (2007). Global Age-Friendly Cities: A Guide. 